\title{
Does Leader Same-sex Sexual Orientation Matter to Leadership Effectiveness? A Four-study Model-testing Investigation
}

\author{
Gang Wang ${ }^{1}\left(\mathbb{D} \cdot\right.$ David S. Steffensen $\mathrm{Jr}^{2} \cdot$ Pamela L. Perrewé ${ }^{1} \cdot$ Gerald R. Ferris ${ }^{1} \cdot$ Samantha L. Jordan ${ }^{3}$
}

Accepted: 14 June 2021 / Published online: 15 July 2021

(c) The Author(s), under exclusive licence to Springer Science+Business Media, LLC, part of Springer Nature 2021, corrected publication 2021

\begin{abstract}
Despite the legalization of same-sex marriage in the United States (U.S.) and an increasing number of out gay and lesbian business leaders, we have little knowledge of the role played by leaders' same-sex sexual orientation in the leadership process. To fill this important research void, we drew from a recent theoretical model on leaders' sexual orientation and conducted four experimental studies designed to test and retest whether leaders' same-sex sexual orientation affects followers' leadership perceptions and conformity to influence attempts, and how the intersectionality of leaders' same-sex sexual orientation with leaders' gender orientation and follower characteristics may modify the influences of leaders' same-sex sexual orientation on the follower outcomes. Based on over 2,100 working adults in the U.S., the results of the four studies, where leaders were depicted as charismatic, indicate that leaders' same-sex sexual orientation could have negative impacts on the follower outcomes. However, same-sex sexual orientation leaders did not suffer double stigma penalization by having additional marginalized identities (e.g., also being women). Female followers were more supportive of same-sex sexual orientation leaders than male followers. Our research advances knowledge of and responds to calls for more research attention to leader sexual orientation in the leadership process. Research and practical implications and directions for future research are discussed.
\end{abstract}

Keywords Leader sexual orientation $\cdot$ Leader gender $\cdot$ Follower conformity $\cdot$ Leadership effectiveness

Recent data suggest that about $2.4 \%$ of adult Americans self-identify as gay or lesbian (LGBT Demographics of the United States, n.d.). As such, leaders with gay or lesbian sexual orientation across hierarchical levels in corporate America, mainly made up of heterosexual employees, constitute a unique minority group (Bialik, 2011; Burns \& Krehely, 2011). Surprisingly, after decades of research on diversity and stigmatized identities in the leadership literature, and after the legalization of same-sex marriage in all 50 states of the United States (U.S.), we have little

Gang Wang

gwang5@business.fsu.edu

1 Department of Management, College of Business, Florida State University, 821 Academic Way, P.O. Box 3061110, Tallahassee, FL 32306-1110, USA

2 Department of Management, Jenings A. Jones College of Business, Middle Tennessee State University, Murfreesboro, TN 37132, USA

3 Department of Management, G. Brint Ryan College of Business, University of North Texas, 1155 Union Circle \#305429, Denton, TX 76203-5017, USA knowledge of the roles played by leaders' same-sex sexual orientation or its intersection with leader gender orientation and follower characteristics in the leadership process (Fassinger et al., 2010). Specifically, Fassinger et al. (2010) commented, "scholarly work on leadership has yet to consider the characteristics and perspectives that sexual minorities - that is, lesbian, gay, bisexual, and transgender (LGBT) individuals - may bring to the process of leadership" (p. 201). This lack of research poses ethical challenges to organizational decision-makers with respect to providing an affirmative work environment for leaders with same-sex sexual orientation.

On one hand, research on minority leaders with stigmatized identities (e.g., gender, race, disabilities) in the leadership literature suggests that sexual minority leaders are likely to be stigmatized, which may undermine their leadership effectiveness (e.g., Colella \& Stone, 2005; Koenig et al., 2011; Martinez et al., 2013; McKay et al., 2009; Sy et al., 2010). Thus, offering extra support for and understanding of leaders with same-sex sexual orientation is justified and necessary. On the other hand, leadership research suggests that due to sexual minority leaders' position and reward power, their same-sex 
sexual orientation would not compromise their leadership effectiveness (e.g., French et al., 1959; Rahim, 1989). If so, the extra support that leaders with same-sex orientation receive from organizations might appear to be unfair and unethical to heterosexual leaders.

In addition, Fassinger et al. (2010) proposed a theoretical framework, which suggests that leaders' sexual orientation matters to their leadership effectiveness. Thus, to advance knowledge on what leaders' sexual orientation brings to the leadership process and to subsequently provide research references to ethical decision making in organizations, we conduct the current research to examine the role leaders' samesex sexual orientation plays in their leadership effectiveness. We draw from Fassinger et al.'s (2010) multidimensional LGBT leadership enactment model to examine whether leaders' same-sex sexual orientation affects follower perceived leadership effectiveness and conformity to leader influence attempts, and how the intersectionality of leaders' same-sex sexual orientation with leaders' gender orientation and follower characteristics may modify the influences of leaders' same-sex sexual orientation on the follower outcomes.

The primary responsibilities of leaders and key outcomes of the leadership process include (a) projecting positive leadership perceptions to followers and (b) successfully mobilizing followers to submit to leadership directives (Bass, 1985; DeRue et al., 2011; Lord \& Maher, 1993). As such, we focus on follower perceptions of leadership effectiveness and follower conformity to leader influence attempts as our outcomes of interest. Moreover, we examine leaders' same-sex sexual orientation because this constitutes a unique sexual minority group that deserves special research attention (Fassinger et al., 2010).

Specifically, as illustrated in Fig. 1, drawing from the LGBT literature and Fassinger et al.'s work-which posits that cultural, societal, and individual stigmas tend to marginalize LGBT leaders-we argue that compared with heterosexual leaders, gay and lesbian leaders will be perceived as less-effective leaders by their followers and receive less conformity to their influence attempts (Blashill \& Powlishta 2009; Herek, 2007, 2008). Moreover, we expect that leaders' gender orientation and situational factors (e.g., follower characteristics) intersect with leaders' same-sex sexual orientation to influence followers' leadership perceptions and conformity to leader influence attempts (e.g., Eagly \& Karau, 2002).

Following recent recommendations for generalizability and reproducibility in organizational research (Hochwarter et al., 2011), we designed a four-study experimental investigation to test and retest the different linkages in our model. In our view, this research contributes to the leadership literature in several important ways. First, diversity and stigmatized identity research in the leadership literature mainly focuses on visible marginalized identities such as leader gender (e.g., Eagly \& Chin, 2010; Schuh, 2014) and race (e.g., Rosette \& Livingston, 2012). Research on concealable stigmatized identities (e.g., leader sexual orientation) is rare (Fassinger et al., 2010).

The current multistudy investigation contributes to leader diversity and stigmatized identity research by revealing whether and when leaders' same-sex sexual orientation, a concealable marginalized identity, may affect followers' perceptions of leadership effectiveness and their conformity to leader influence attempts. The findings of this investigation provide important theoretical implications for leader diversity and stigmatized identity research, such as invoking the intersectional invisibility perspective (Purdie-Vaughns \& Eibach, 2008). Adding to dominant theories regarding various leadership styles or behaviors in the leadership literature (e.g., Bass, 1985; Tepper, 2000; Yukl, 2010), our theoretical framework suggests a novel
Fig. 1 Theoretical model of the current research

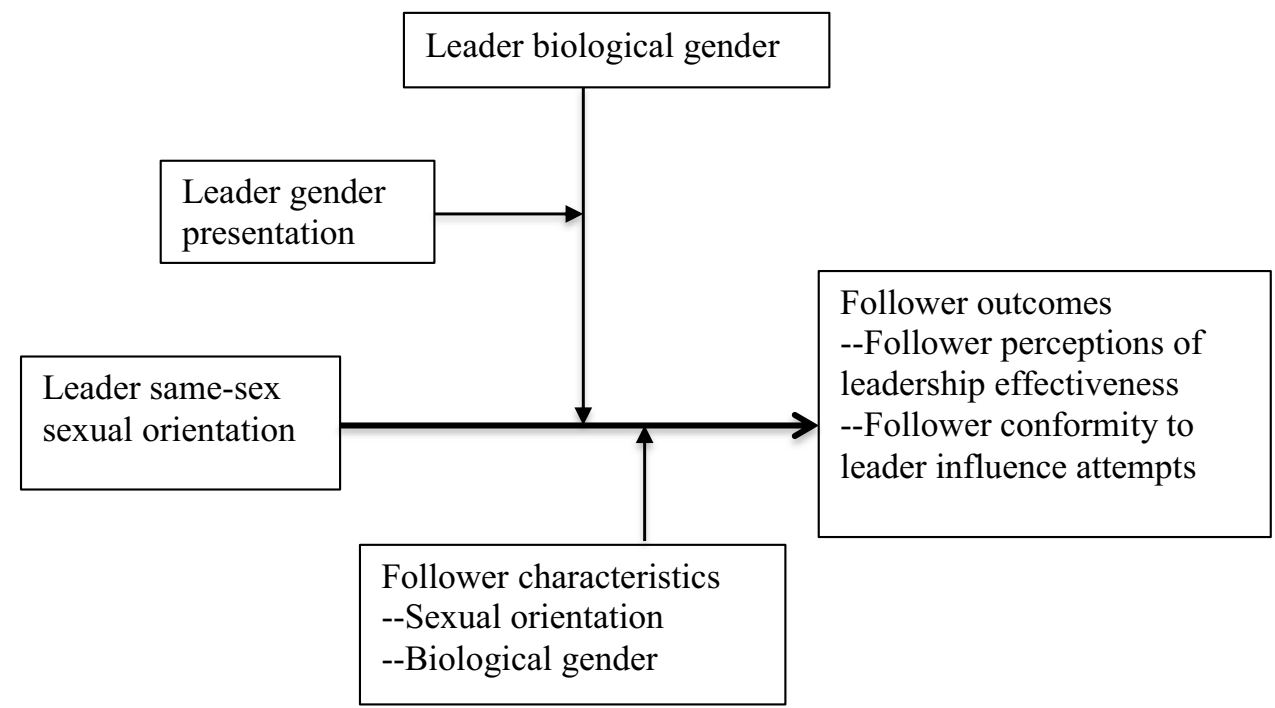


and complementary lens of understanding leaders' influences on followers in the leadership process.

Second, the current four-study investigation represents one of the first attempts at partially testing the validity of Fassinger et al.'s (2010) multidimensional LGBT leadership enactment model, which posits that leader sexual orientation, gender orientation, and situation constitute three dimensions that collectively influence sexual minority leaders' leadership in organizations. The findings of this research contribute to the precision and refinement of this theoretical model. For instance, our findings suggest that the additive model of intersection (e.g., Rosette \& Livingston, 2012), which posits that the addition of each subordinate identity leads to more deleterious results, might not be a valid perspective to understand the intersection between leaders' same-sex sexual orientation and their gender orientation. Instead, the interactive model of intersection, which submits that individuals with multiple marginalized identities have a unique social location and that increases of marginalized identities may not necessarily bring worse outcomes (Reece, 2019), appears to be an appropriate perspective.

Third, this investigation also offers much-needed ethical implications for various stakeholders, such as organizational decision-makers, sexual minority leaders, and followers. For instance, given the lack of research in this area, sexual minority leaders may have little understanding regarding the extent to which their sexual orientation may compromise their influences on followers, or which followers may be more or less accepting of their sexual orientation. Such knowledge not only sheds light on some of the challenges that sexual minority leaders face but also helps them decide whether to disclose their sexual orientation at work. Further, this research helps to elucidate the ethical issues surrounding the organizational selection and promotion decisions of gay and lesbian employees into leadership positions. In the following sections, we first review the literature on leaders with stigmatized identities, then introduce the theoretical perspectives that support our investigation, and, in turn, detail the four studies designed to test and retest our theoretical model illustrated in Fig. 1.

\section{Research on Leaders with Stigmatized Identities}

There is a growing stream of research in the leadership literature that focuses on leaders with stigmatized identities. Theory and evidence consistently indicate that prototypical leaders are white, male, and masculine (Koenig et al., 2011; Rosette et al., 2008). Leaders who do not possess the prototypical leader characteristics are believed to be incongruent with leadership roles and subject to extra scrutiny, marginalization, and discrimination (Eagly \& Karau, 2002).
A substantial amount of research has been conducted to understand the unique experiences of female leaders across organizational hierarchies (e.g., Hill et al., 2015; Johnson et al., 2008; Lewis, 2000; Ragins, 1989; Ryan \& Haslam, 2007). In general, despite being just as effective as male leaders, female leaders are found to be in a disadvantageous position when compared to equivalent male counterparts (Eagly \& Johnson, 1990; Eagly \& Karau, 1991; Eagly et al., 1995). In fact, even female CEOs face more obstacles and are paid less than male CEOs (Jeong \& Harrison, 2017; Wang et al., 2018).

Researchers also have considered the significant implications of racial minority leadership, with a specific focus on black (Bartol et al., 1978; Ospina \& Foldy, 2009) and Asian and Hispanic leaders (e.g., Sy et al., 2010; Zapata et al., 2016). This body of research examines the roles racial minority leaders play across a variety of impactful outcomes (e.g., follower leadership perceptions and evaluations, leadership behaviors, leader work attitudes, leader job performance, consumer purchasing behavior, team effectiveness, etc.) (e.g., Avery et al., 2015; Sy et al., 2010). The results vary, are nuanced, and sometimes contingent on other factors. That said, rarely, if ever, did racial minority leaders fare better in the outcomes of interest than their non-minority counterparts.

Additionally, scholars have examined black female leaders, who have dual-subordinate identities (e.g., Rosette \& Livingston, 2012; Rosette et al., 2016). The limited findings so far suggest black female leaders tend to suffer a double stigma penalization, where they are viewed even more unfavorably because they fall into more than one marginalized group (i.e., female and black). Finally, there also is limited and sporadic research on weight-based discrimination against leaders (Lynch, 2019). Taken together, research on leaders with stigmatized identities has been centered around visible marginalized characteristics and starts to examine the intersectionality of different stigmatized identities.

\section{Theoretical Framework and Hypothesis Development}

Although there has been some research on sexual minorities in colleges and at work (e.g., Goodman et al., 2008; Hoye $\&$ Lievens, 2003; King et al., 2017; Pellegrini et al., 2020), scholarship on adult sexual minority leaders is scant. As an exception, Snyder (2006) reported positive outcomes associated with gay male executives, such as increased follower job satisfaction and engagement. However, this study was criticized for methodological flaws (Fassinger et al., 2010) and did not examine lesbian female leaders or the intersections of gay male leaders' sexual orientation with their gender orientation or situation. 
Conceptually based on intersectionality, Fassinger et al. (2010) developed a multidimensional LGBT leadership enactment model representing one of the first theoretical frameworks to explore how leaders' sexual orientation operates in the leadership process. Intersectionality reflects the notion that there is no single identity category that describes how we respond to our social environment, or how we are responded to by others (Shields, 2008). Much of the research on intersectionality has been focused on the experiences of groups holding multiple disadvantaged statuses (e.g., Crenshaw, 1991; Grzanka $\&$ Miles, 2016). Intersectionality researchers have argued that considering categories such as sexuality and gender independently may be limited because individuals experience these statuses simultaneously (Cole, 2009). Further, researchers recently have argued that intersectionality provides a theoretical lens for highlighting barriers to effective leadership (Breslin et al., 2017).

Drawing from the LGBT literature, Fassinger et al. (2010) posit that cultural, societal, and individual stigmas tend to marginalize LGBT leaders. As one dimension of Fassinger et al.'s model, leaders' sexual orientation may affect their own perceptions, and others' judgments, of their leadership effectiveness, as well as their own and others' behaviors. Sexual minority leaders are subject to sexual prejudice that "homosexuality" is sick, immoral, or evil (e.g., Blashill \& Powlishta, 2009; Goodman et al., 2008; Herek, 2007, 2008). As such, gay or lesbian leaders may carry "different sensibilities, values, skills, and experiences to the task of leadership" (Fassinger et al., 2010, p. 208).

In addition, Fassinger et al. (2010) argued that the second dimension in their model, leaders' gender orientation, may intersect with leaders' sexual orientation to impact the leadership process. Fassinger et al. (2010) defined gender orientation as "the way in which each individual's gender is expressed," which includes "not only biological/physiological/assigned gender, but also gender roles, attitudes, cognitions, behavior, and presentation" (p. 210). Drawing from research on gender role stereotypes, which posits that leadership roles are stereotypically occupied by males (Koenig et al., 2011; Yoder, 2001), Fassinger et al. (2010) argued that leaders' biological gender will intersect with their sexual orientation. Specifically, because gay leaders meet leader gender role expectations, attention and scrutiny will be focused on their sexual orientation, or how much they are perceived as "real men." Thus, in line with the manager-as-male stereotype (Dodge, Gilroy, \& Fenzel, 1995), not only does gender matter in shaping perceptions of leadership but also the male-oriented stereotypical characteristics we ascribe to leadership positions (e.g., leaders are assertive, independent, masculine, self-confident, etc.) also have an impact.
However, for lesbian leaders, they violate both leader gender role expectations and sexual orientation expectations, which put them in a double-bind situation. If they behave like "real" women, they are perceived to be less effective as leaders. If they "transgress" and behave like men, rather than behaving congruently with normative standards for biological women, they confirm sexual orientation stereotypes (i.e., lesbians are perceived to act in masculine ways) and are at greater risk of more negative reactions by followers (Lehavot \& Lambert, 2007).

The last dimension of Fassinger et al.'s (2010) model is situation, where the authors placed particular emphasis on followers. They suggested that followers' experiences, predispositions, worldviews, and sexual orientation will intersect with leaders' sexual orientation. They maintained that these situational factors may shape followers' expectations and acceptance of leaders' sexual orientation and, therefore, influence the role leaders' sexual orientation plays in the leadership process. As an example, Fassinger et al. (2010) reasoned that sexual minority leaders who express their sexual identity are perceived as more effective leaders among followers who are predominantly non-heterosexual than among followers who are mainly heterosexual.

Fassinger et al.'s (2010) model suggests various possible influences of leaders' sexual orientation, such as influences on leaders' own behavior, self-concept, leadership competencies, and followers' perceptions and behaviors. In our four-study investigation, as noted earlier, we choose to study leaders with same-sex sexual orientation (i.e., gay and lesbian leaders) and focus on the influences of leaders' samesex sexual orientation on followers' perceptions of leadership effectiveness and conformity to leaders' influence attempts.

\section{Study 1: Hypothesis Development}

According to Fassinger et al. (2010), leaders with same-sex sexual orientation are sexual minorities in organizations that are predominantly made up of heterosexual individuals. These leaders are subject to followers' sexual prejudice resulting from cultural, societal, and individual stigma toward same-sex individuals (e.g., Blashill \& Powlishta, 2009; Goodman et al., 2008; Herek, 2007, 2008). In contrast, leaders with heterosexual orientation do not suffer such sexual prejudice from their followers. In our society, heterosexuality is the default. That is, individuals tend to presume and prefer heterosexuality in others. These presumptions and preferences, known as heteronormativity (Warner, 1991), affect individuals' perceptions of others.

Individuals who violate heteronormative standards are viewed as inferior and incompetent (Pichler \& Holmes, 2017). Further, individuals who violate heteronormativity are often the targets of microaggressions that alienate 
and disparage them (Platt \& Lenzen, 2013). These views and subsequent reactions are found in organizational settings (Krupat \& McCreery, 2001). Unlike straight employees, gay and lesbian employees violate the standards of heteronormativity and these violations are further compounded when gay and lesbian individuals aspire or hold leadership roles, which are often laden with even more stringent heteronormative expectations. Thus, when leaders engage in behavioral manifestations of their sexual orientation, violators of our society's heteronormative standards-in this case, gay and lesbian leaders-will be "punished" by their followers. These "punishments" may occur via followers' perceptions of their leaders' characteristics and behaviors, evaluations of their leadership effectiveness, or in their own personal job performance. As such, followers are likely to perceive leaders with same-sex sexual orientation as less effective and are less likely to conform to the leaders' influence attempts, as these leaders are presumed to be inferior to stereotypical leaders (e.g., Blashill \& Powlishta, 2009; Koenig et al., 2011; Sy et al., 2010). Therefore, we propose the following hypothesis.

Hypothesis 1: Compared with heterosexual leaders, leaders with same-sex sexual orientation will (1a) be perceived as lower in leadership effectiveness by their followers and ( $1 \mathrm{~b})$ receive less follower conformity to their influence attempts.

In addition, Fassinger et al.'s (2010) theoretical model suggests leaders' gender orientation may intersect with leaders' same-sex sexual orientation in influencing followers. As noted earlier, Fassinger et al. (2010) argued that gender orientation includes both biological gender and gender presentation (i.e., whether one behaves in a masculine or feminine way). Research on gender roles (Eagly \& Karau, 2002) consistently has shown that leadership roles are believed to be held by men, and stereotypically ascribed to be masculine in society (e.g., Koenig et al., 2011).

Thus, when lesbian women occupy leadership roles, there is an incongruity between their biological sex and the leadership role. They violate gender role stereotypes and are susceptible to prejudice related to descriptive norms, "which are consensual expectations about what members of a group actually do" (Eagly \& Karau, 2002, p. 574). Driven by such descriptive norms, perceivers tend to regard lesbian leaders as less qualified than gay leaders because the former are women, not men. Thus, followers whose leaders are lesbian tend to perceive their leaders as less effective, and they demonstrate less conformity to their leaders' influence attempts than followers whose leaders are gay.
Hypothesis 2: Compared with gay leaders, lesbian leaders will (2a) be perceived as lower in leadership effectiveness by their followers and ( $2 b$ ) receive less follower conformity to their influence attempts.

\section{Study 1: Method}

\section{Participants and Design}

Because of the sensitivity and ethical concerns of the topic, we followed Aguinis and Bradley's (2014) recommendations and adopted an experimental vignette methodology (i.e., scenario or paper people studies) to test our hypotheses across all four studies in this investigation. This methodology allows us to test causal effects while addressing ethical dilemmas (Aguinis \& Bradley, 2014). Given that we intended to examine the effects of leader sexual orientation on followers in corporate America, we recruited adults who worked as followers (i.e., full-time employees who report to a direct supervisor) in American companies through Amazon's eLancing site, Mechanical Turk (M-Turk).

eLancing data have been used in prior research in the organizational sciences (e.g., Caleo, 2016; Piccolo \& Colquitt, 2006). According to Aguinis and Lawal (2012, 2013), eLancing provides a natural environment for researchers to conduct field experiments, allowing researchers to not only recruit participants quickly and less costly, but also to "improve generalizability, address the omitted variables problem, improve the operationalization of constructs, improve confidence regarding the nature of relationships, and address other challenges such as participant bias" (Aguinis \& Lawal, 2012, p. 493).

Nine hundred twenty-eight working adults in the U.S. were recruited through M-Turk to take part in our research. Forty participants failed an attention check question and were immediately bumped off the data collection process. Among the 888 respondents who participated in our research and passed the attention check question, eight did not respond to the measure for follower conformity to leader influence attempts. Complete data were available for 880 respondents. Fifty-six percent of the respondents were female, $43 \%$ were male, and three individuals identified themselves as neither male nor female. The average age of the respondents was 38.75 years $(S D=10.59)$. Thirty-seven percent reported having personal experience working with gay or lesbian leaders. Ninety percent of the respondents identified as heterosexual. The remaining selected "other" as their sexual orientation.

To test the Study 1 hypotheses, we adopted a $2 \times 2$ factorial between-subject experimental design with leader sexual orientation (i.e., same-sex or heterosexual) and 
leader biological gender (i.e., male or female) as independent variables, and follower perceptions of leadership effectiveness and conformity to leader influence attempts as dependent variables respectively. Participants were randomly selected into each of the four vignettes.

\section{Procedure}

With reference to prior research (e.g., Blashill \& Powlishta, 2009; Lehavot \& Lambert, 2007), we manipulated leaders' sexual orientation and biological gender using typical gender-specific first names (i.e., Robert and Mary), corresponding normative pronouns (his/her), and their spouses' first names. Specifically, as shown in a sample vignette in Appendix 1, by introducing "Robert" (or "Mary") as the head of a marketing department, we manipulated the leader's biological gender. Moreover, by introducing "his" (or "her") spouse as "Greg" or "Linda" (or "Linda" or "Greg"), we manipulated the leader's sexual orientation.

Next, the supervisors' leadership behaviors were described. With reference to the scripts used by Grinnell (2002) and Powell et al. (2008), and using Conger and Kanungo's (1987) behavioral components of charismatic and non-charismatic leaders, we described the supervisor as a charismatic leader. These components have been validated in previous research (e.g., Vlachos et al., 2013). Identical information regarding the supervisor's charismatic leadership behaviors was provided across all four vignettes. By holding leadership behaviors constant, we wanted to exclude potential confounding effects of leadership behaviors on the influences of leader same-sex sexual orientation on follower outcomes.

After reading the vignettes, participants were asked to assess "their supervisor's" effectiveness. Next, they were told that "their supervisor" wanted them to write down as many uses of a brick as possible in three minutes. The number of viable uses was counted as a measure of the participants' conformity. This task, known as the Brick Uses Test (Guilford, 1975), has been used in previous studies (e.g., Frick et al., 1959; Porath \& Erez, 2007). In the current research, we adapted the Brick Uses Test to make it a higher fidelity activity. We told participants that the marketing firm for which they worked was approached by a brick manufacturer that was looking to expand its clientele, and thus needed help marketing its product to new customers. In addition, participants were asked to assess "their supervisor's" sexual orientation as a manipulation check. To ensure data quality, we also added an attention check question. Finally, we asked participants to report their demographic information, including their age, education level, gender, sexual orientation, years of work experience, and whether they had ever worked with a gay or lesbian supervisor.

\section{Measures}

Manipulation check To verify that participants remembered the manipulations, we asked them to rate "their supervisor's" sexual orientation using an adapted one-item Klein Sexual Orientation Grid (KSOG; Klein et al., 1985) on a 7-point scale ranging from "heterosexual only (1)" to "homosexual only (7)."

Follower perceptions of leadership effectiveness We measured this construct with a six-item scale $(\alpha=0.95)$ used by Giessner and van Knippenberg (2008). Sample items include: "Robert (Mary) is a good leader," "Robert (Mary) is very effective," and "I like working together with Robert (Mary)."

Follower conformity to leader influence attempts We used the number of viable uses of brick that participants wrote down as a measure of their conformity to leader influence attempts. The authors of the paper independently counted the uses, and their interrater reliability was high (their codes correlated at 0.93 ).

\section{Study 1: Results}

\section{Manipulation Checks}

We conducted a two-way analysis of variance (ANOVA) on followers' perceptions of the leaders' sexual orientation. The two-way ANOVA results indicated that our manipulation of leaders' sexual orientation was successful. There was a significant main effect of leaders' sexual orientation on followers' perceptions of the leaders' sexual orientation, $F(1$, $884)=1123.71, p<0.001, \eta_{p}^{2}=0.56$, such that leaders in the same-sex conditions were rated much higher on same-sex sexual orientation $(M=5.63 ; S D=2.10)$ than leaders in the heterosexual conditions $(M=1.79 ; S D=1.21)$. Neither the main effect of leader biological gender nor the interaction between leader sexual orientation and biological gender was significant.

\section{Hypothesis Testing Results}

Hypothesis la posited that leaders with same-sex sexual orientation (i.e., gay and lesbian leaders) would be perceived to be less effective by their followers than heterosexual leaders. As shown in Table 1 (Two-way ANOVA analysis on follower perceptions of leadership effectiveness), a twoway ANOVA analysis on follower perceptions of leadership effectiveness shows that there was a significant main effect of leaders' sexual orientation, $F(1,884)=4.07, p=0.044$ ). Neither the main effect of leaders' biological gender nor the 
Table 1 Study 1 results

\begin{tabular}{|c|c|c|c|c|c|}
\hline Variables & $d f$ & Mean square & $F$ & Significance & $\eta_{p}^{2}$ \\
\hline \multicolumn{6}{|c|}{ Two-way ANOVA analysis on follower perceptions of leadership effectiveness ${ }^{a}$} \\
\hline Leader sexual orientation (LSO) & 1 & 3.03 & 4.071 & .044 & .002 \\
\hline Leader biological gender (LBG) & 1 & 1.403 & 1.885 & .170 & .005 \\
\hline $\mathrm{LSO} * \mathrm{LBG}$ & 1 & .383 & .515 & .473 & .001 \\
\hline Error & 884 & .744 & & & \\
\hline \multicolumn{6}{|c|}{ Two-way ANOVA analysis on follower conformity to leader influence attempts ${ }^{b}$} \\
\hline Leader sexual orientation (LSO) & 1 & 208.075 & 8.676 & .003 & .010 \\
\hline Leader biological gender (LBG) & 1 & 751.123 & 31.32 & .000 & .035 \\
\hline LSO * LBG & 1 & 58.280 & 2.430 & .119 & .003 \\
\hline Error & 876 & 23.982 & & & \\
\hline
\end{tabular}

interaction between leaders' sexual orientation and biological gender was significant. Consistent with Hypothesis la's prediction, the results of planned contrast analysis reveal that leaders with same-sex sexual orientation (i.e., gay and lesbian leaders) $(M=6.04 ; S D=0.89)$ were perceived to be significantly less effective than heterosexual leaders $(M=6.15$; $S D=0.83$ ).

Hypothesis $1 b$ predicted that leaders with same-sex sexual orientation would receive less conformity to their influence attempts from their followers than heterosexual leaders. As summarized in Table 1 (Two-way ANOVA analysis on follower conformity to leader influence attempts), a two-way ANOVA analysis on follower conformity to leader influence attempts demonstrates that there was a significant main effect of leaders' sexual orientation, $F(1,876)=8.68, p=0.003$. The main effect of leaders' biological gender was also significant, $F(1,876)=31.32, p<0.001$, whereas the interaction between leaders' sexual orientation and biological gender was not significant. Supporting Hypothesis $1 b$, the results of planned contrast analysis indicate that leaders with same-sex sexual orientation (i.e., gay and lesbian leaders) $(M=9.58 ; S D=4.75)$ received significantly less follower conformity than heterosexual leaders $(M=10.53 ; S D=5.21)$. Taken together, Hypothesis $l a$ and $l b$ were supported.

Hypothesis $2 a$ proposed that lesbian leaders would be perceived as less effective than gay leaders. The results of planned contrast analysis reveal that there was not a significant difference $(F(1,884)=0.21, p=0.645)$ in perceived leadership effectiveness between lesbian $(M=6.06 ; S D=0.86)$ and gay $(M=6.02$; $S D=0.93$ ) leaders. Thus, Hypothesis $2 a$ was not supported. Hypothesis $2 b$ predicted that lesbian leaders would receive less conformity to their influence attempts than gay leaders. Contrary to Hypothesis $2 b$, the results of planned contrasts show that lesbian leaders $(M=10.24 ; S D=5.31)$ received significantly $(F(1,876)=8.06, p=0.005)$ more conformity to their influence attempts than gay leaders $(M=8.91 ; S D=3.99)$.

\section{Study 1: Discussion}

The main purpose of Study 1 was to examine whether leader same-sex sexual orientation affects follower leadership perceptions and conformity to leader influence attempts, as well as the intersection between leader same-sex sexual orientation and leader biological gender. The above results suggest that leaders' same-sex sexual orientation undermines their role as effective leaders, in that same-sex leaders are perceived by their followers to be less effective and receive less conformity from their followers than heterosexual leaders. These findings provide fresh evidence for the discrimination that leaders with same-sex sexual orientation may face and are also consistent with prior findings that minority (e.g., sexual minority and demographic minority) people face unwarranted discrimination in society and at work.

The concealable nature of same-sex sexual orientation sets it apart from other visible marginalized characteristics (e.g., sex, race, physical disability, etc.), and raises questions on whether findings on the visible marginalized characteristic would be generalizable to nonvisible marginalized groups as well. Our results showing that same-sex leaders are perceived to be less effective and receive less follower conformity than heterosexual leaders indicate that, like others with visible marginalized characteristics, same-sex leaders tend also to suffer discrimination once their same-sex sexual orientation becomes evident to followers.

Results of the intersection between leaders' same-sex sexual orientation and biological gender reveal some unexpected and interesting findings. To be noted, it appears that same-sex leaders' biological gender makes no difference in follower perceptions of leadership effectiveness. This finding is different from past evidence that male leaders were repeatedly believed to be more effective leaders than female leaders (Koenig et al., 2011). It could be that followers categorized same-sex leaders into the same group 
regardless of their biological gender. Nonetheless, our finding suggests potential caveats in understanding prior research on gender differences in leadership and calls into question the commonly used additive model of intersectionality in diversity research (e.g., Keith et al., 2017; Livingston et al., 2012; Rosette \& Livingston, 2012). Different from what an additive model would predict, this finding indicates that same-sex leaders' biological gender did not add insult to injury.

Perhaps the most unexpected finding in Study 1 was that lesbian leaders received more conformity to their influence attempts than gay leaders. Prior research on leader gender differences generally suggests male leaders tend to gain more conformity from followers than female leaders (e.g., Eagly \& Karau, 1991, 2002). Our finding that lesbian leaders had an edge at gaining follower conformity over gay leaders adds nuanced knowledge to the literature of leader gender differences. Research on gender inversion may shed light on this unexpected finding (Clausell \& Fiske, 2005; Herek, 2002; Kite \& Deaux, 1987; Madon, 1997; Taylor, 1998). According to scholarship on gender inversion, people stereotypically assume gay men to behave like women, and lesbians to behave like men.

In the four vignettes in the current study, no information on the gay and lesbian leaders' gender presentation (i.e., whether they behave in a masculine or feminine way) was provided. Thus, it was likely that study participants' gender inversion stereotypes against gay and lesbian made them implicitly assume that the gay leaders behaved like women and that lesbian leaders behaved like men (Kite \& Deaux, 1987). As a result, research on the masculinity of leader stereotypes (e.g., manager-as-male stereotype; Dodge et al., 1995) suggests study participants might have shown more conformity to lesbian leaders than to gay leaders (Koenig et al., 2011; Shinar, 1975).

\section{Study 2: Hypothesis Development}

Although Study 1 did not find the expected intersection between leader same-sex sexual orientation and biological gender, research on gender inversion suggests that the intersection could be contingent upon leader gender presentation (Ellis, 1927; Kite \& Deaux, 1987; Madon, 1997; Taylor, 1998). Thus, in Study 2, we investigate how leader gender presentation may affect the intersection between leader same-sex sexual orientation and biological gender. In addition, bringing in the third dimension in Fassinger et al.'s (2010) theoretical model, we examine whether follower characteristics may intersect with leader same-sex sexual orientation to influence follower leadership perceptions and conformity to leader influence attempts.

As noted earlier, research on gender inversion suggests that gay men are stereotypically believed to behave like women, whereas lesbians are believed to behave like men (Clausell \& Fiske, 2005; Herek, 2002; Kite \& Deaux, 1987; Madon, 1997; Taylor, 1998). Thus, followers often expect gay leaders to behave femininely and lesbian leaders to behave masculinely. Compared with gay leaders who behave masculinely, gay leaders who behave femininely further violate leader gender role stereotypes (i.e., they should behave masculinely like men). We argue that such feminine behaviors tend to cue their followers to pay increased attention to their same-sex sexual identity. Therefore, gay leaders' gender presentation may modify the effects of their same-sex sexual orientation on followers' leadership perceptions and behaviors, in such a way that gay leaders who appear to be feminine tend to be perceived as less effective and receive less conformity to their influence attempts than gay leaders who appear to be masculine. Empirical evidence in the LGBT literature shows that feminine gay males were perceived more negatively than masculine gay males by predominately heterosexual males and females (Blashill \& Powlishta, 2009; Lehavot \& Lambert, 2007), suggesting a plausible intersection between gay leaders' sexual orientation and their gender presentation.

In addition, lesbian leaders who behave in a masculine way fall under stereotypes about lesbians, and are believed to be less effective than lesbian leaders who behave femininely (Lehavot \& Lambert, 2007), because the former violates leader gender role stereotypes and injunctive norms (i.e., they are women and should behave femininely like women). Similarly, we argue that lesbian leaders' masculine behaviors tend to cue their followers to attend to their same-sex sexual identity and that compared with the latter, the former is likely to receive less conformity to their influence attempts. Empirically, Lehavot and Lambert (2007) reported that heterosexual individuals disliked masculine lesbians to a greater extent than feminine lesbians.

Hypothesis 3: For leaders with same-sex sexual orientation, their biological gender, and gender presentation interact, such that feminine gay leaders tend to (3a) be perceived as lower in leadership effectiveness by their followers and (3b) receive less follower conformity to their influence attempts than masculine gay leaders, and that masculine lesbian leaders tend to $(3 \mathrm{c})$ be perceived as lower in leadership effectiveness by their followers and (3d) receive less follower conformity to their influence attempts than feminine lesbian leaders.

Moreover, Fassinger et al. (2010) argued that followers' worldviews serve as a third dimension that also may intersect with leaders' sexual orientation. Two follower characteristics that reflect follower distinct identities and worldviews, and are relevant to their receptivity of leaders' same-sex sexual 
orientation, are follower sexual orientation and biological gender. First, it stands to reason that heterosexual and nonheterosexual (i.e., sexual minority) followers react differently to leaders with same-sex sexual orientation. As noted earlier, due to homophobia towards gay and lesbian individuals and stereotypes regarding prototypical leaders, heterosexual followers tend to perceive leaders with same-sex sexual orientation as less effective and exhibit low levels of conformity to these leaders' influence attempts.

In contrast, sexual minority followers are more likely to identify socially with their sexual minority leaders and categorize them as in-group members (Avolio, 2007; Chatman, 1991; Tajfel \& Turner, 1985). As such, these followers are less likely to be distracted by their leaders' same-sex sexual orientation. Taken together, for same-sex leaders, their nonheterosexual followers tend to perceive them as more effective and demonstrate higher levels of conformity than their heterosexual followers. Empirically, findings that gay and lesbian individuals experienced more discrimination in predominantly heterosexual workgroups than in sexual minority groups (Ragins \& Cornwell, 2001) provide some support to the above arguments.

Hypothesis 4: For leaders with same-sex sexual orientation, their heterosexual followers tend to perceive them as lower in leadership effectiveness (4a) and are less likely to conform to their influence attempts (4b) than their nonheterosexual followers.

Second, abundant research on gender differences suggests that male and female followers face different role norms and form different worldviews (e.g., Eagly, 1987; Eagly \& Johnson, 1990). According to social role theory, societal norms and practices regarding gender roles maintain that men and women are expected to occupy roles corresponding with stereotypical attributes of men and women (Eagly \& Johannesen-Schmidt, 2001). With respect to leader-follower roles, because "stereotypes of leaders are decidedly masculine" (Koenig et al., 2011, p. 634), female followers are expected to accept their low-status follower roles, be receptive and submissive to their leaders, and behave in a communal way such as being kind, helpful, and compassionate more than their male counterparts (e.g., Eagly \& Johnson, 1990; Koch et al., 2015).

Conforming to such social norms and pressure, female followers are more likely to internalize the follower role expectations and become more obedient to and supportive of leaders than male followers (e.g., Duehr \& Bono, 2006; Eagly \& Johnson, 1990; Lord et al., 1980). By extension, compared with their male counterparts, female followers tend to tolerate to a greater extent same-sex leaders' non-stereotypical sexual orientation. As such, female followers may perceive their same-sex leaders to have higher levels of leadership effectiveness and are more likely to conform to their influence attempts than male followers. In support, Lehavot and Lambert (2007) reported that female undergraduate participants rendered less harsh judgments of gay men than did male undergraduate participants.

Hypothesis 5: For leaders with same-sex sexual orientation, their female followers (5a) tend to perceive them as higher in leadership effectiveness and (5b) are more likely to conform to their influence attempts than male followers.

\section{Study 2: Method}

\section{Participants}

As in Study 1, we recruited study participants through Amazon's M-Turk to take part in our research in Study 2. In order not to include Study 1 participants, the invitations for Study 2 were not sent to those who responded to Study 1 using their M-Turk IDs. Nine hundred and nineteen working adults in the U.S. participated. Forty-three respondents failed an attention check question and were instantaneously excluded from the study. Among the 876 participants who passed the attention check question, 14 did not respond to the measure of followers' conformity to leader influence attempts. Complete data were available for 862 working adults in the U.S. Fifty-five percent of the respondents were female, $45 \%$ were male, and five individuals identified themselves as neither male nor female. The average age of the respondents was 37.44 years $(S D=10.05)$. Forty-one percent reported working with gay or lesbian leaders, whereas $59 \%$ did not have such experiences. Eighty-nine percent of respondents identified as heterosexual. The remaining selected "other" as their sexual orientations.

As in Study 1, we implemented a $2 \times 2$ factorial betweensubject experimental design with same-sex leaders' gender expression (i.e., behaving masculinely or behaving femininely) and leader biological gender (i.e., male or female) as independent variables, and follower perceptions of leadership effectiveness and conformity to leader influence attempts as dependent variables respectively. Participants were randomly selected into each of the four vignettes.

\section{Procedure}

We designed this study to test Hypothesis 3, which predicted that same-sex leaders' gender presentation and biological gender would interactively affect follower leadership effectiveness perceptions and conformity to leader influence attempts. The same procedure and design as in Study 1 were used. The vignette for the gay male supervisor (Robert 
whose spouse is Greg) and the vignette for the lesbian supervisor (Mary whose spouse is Linda) in Study 1 were adapted. We manipulated Robert's (Mary's) gender presentation by introducing his (her) after-work hobbies. In the masculine condition, Robert (Mary) was portrayed as someone who enjoys masculine activities such as "rock-climbing, camping, and brewing craft beer." In the feminine condition, Robert (Mary) was described as someone who likes feminine activities such as "baking, reality TV, and repurposing vintage clothes and knick-knacks to sell on his (her) online store." Like in Study 1, leader biological gender was manipulated using typical gender-specific first names (i.e., Robert and Mary) and pronouns (i.e., his and her).

\section{Measures}

The survey measures (e.g., follower perceptions of leadership effectiveness $[\alpha=0.95])$ used in Study 1 also were used in Study 2. For follower conformity to leader influence attempts, we asked participants to think of uses for wood rather than brick because one participant in Study 1 indicated that s/he had been asked to complete a similar activity in the past. The reliability estimate for follower conformity was computed via interrater reliability (the authors independently coded the number of uses for wood, and their codes correlated at 0.97). Finally, following prior research (e.g., Goodman et al., 2008; Lehavot \& Lambert, 2007), we asked participants to rate the vignette leaders' masculinity and femininity along a scale from "not at all (0)" to "extremely (10)" and reverse-coded scores for femininity. The average of the two ratings was used to check our manipulations of leaders' gender presentation. Follower sexual orientation was measured with a dummy variable (i.e., $0=$ heterosexual; $1=$ non-heterosexual), and follower biological gender was coded with a dummy variable (i.e., $0=$ male; $1=$ female).

\section{Study 2: Results}

\section{Manipulation Checks}

We performed a two-way ANOVA to see whether our manipulation of gay and lesbian leaders' gender presentation was successful. The results revealed a significant main effect of same-sex leaders' gender presentation on followers' perceptions of the leaders' masculinity, $F(1,872)=1,762.39$, $p<.001, \eta_{p}^{2}=0.67$, such that the leaders in masculine conditions $(M=5.62 ; S D=1.11)$ were perceived to be significantly higher in masculinity than those in feminine conditions $(M=2.54 ; S D=1.06)$. Neither the main effect of leader biological gender nor the interaction between leader gender presentation and biological gender was significant.

\section{Hypothesis Testing Results}

To rule out potential confounding effects of followers' sexual orientation and biological gender, we performed a factorial analysis of covariance (ANCOVA) with the two variables as covariates. As shown in Table 2 (Two-way ANCOVA analysis on follower perceptions of leadership effectiveness), a two-way ANCOVA analysis on follower perceptions of leadership effectiveness was conducted, and there were no significant main effects or interactions between samesex leaders' biological gender and gender presentation. The results of planned contrasts show that there was not a significant difference between feminine $(M=6.08 ; S D=1.00)$ and masculine $(M=6.07 ; S D=0.98)$ gay leaders with respect to their leadership effectiveness $(F(1,862)=0.00, p=0.987)$. Thus, Hypothesis $3 a$, which predicted that feminine gay leaders would be perceived as less effective than masculine gay leaders, was not supported. Additionally, the results of planned contrasts show that there was not a significant difference between masculine $(M=6.10 ; S D=0.89)$ and feminine $(M=6.09 ; S D=0.85)$ lesbian leaders with respect to their leadership effectiveness $(F(1,862)=0.02, p=0.890)$. Thus, Hypothesis $3 c$, which predicted that masculine lesbian leaders would be perceived as less effective than feminine lesbian leaders, was not supported.

Moreover, as summarized in Table 2 (Two-way ANCOVA analysis on follower conformity to leader influence attempts), the results of a two-way ANCOVA on follower conformity to leader influence attempts indicate that the main effects of same-sex leaders' biological gender and gender presentation were not significant, and the interaction between samesex leaders' biological gender and gender presentation was not significant either. Planned contrasts were conducted to test Hypothesis $3 b$, which posited that feminine gay leaders would receive less follower conformity than masculine gay leaders. The results of planned contrasts show that there was not a significant $(F(1,851)=1.03, p=0.311)$ difference in follower conformity between feminine $(M=14.01$; $S D=7.53)$ and masculine $(M=13.12 ; S D=6.69)$ gay leaders. Thus, Hypothesis $3 b$ was not supported. In addition, the results of planned contrasts illustrate that there was not a significant $(F(1,851)=0.17, p=0.684)$ difference in follower conformity between masculine $(M=14.30 ; S D=6.66)$ and feminine $(M=14.51 ; S D=10.66)$ lesbian leaders. Thus, Hypothesis $3 d$ was not supported.

Hypothesis 4 posited that same-sex leaders' heterosexual followers would perceive them as less effective (Hypothesis $4 a$ ) and exhibit less conformity (Hypothesis $4 b$ ) than their non-heterosexual followers. Independent $t$-test results, based on the four conditions in Study 2, revealed that there were not significant differences between non-heterosexual followers and heterosexual followers regarding their leadership perceptions $(t(871)=-0.61, p=0.543$, 
Table 2 Study 2 results

\begin{tabular}{|c|c|c|c|c|c|c|c|c|}
\hline Variables & $d f$ & Mean square & $F$ & & \multicolumn{2}{|c|}{ Significance } & $\eta_{p}^{2}$ & \\
\hline \multicolumn{9}{|c|}{ Two-way ANCOVA analysis on follower perceptions of leadership effectiveness ${ }^{a}$} \\
\hline \multicolumn{9}{|l|}{ Covariates } \\
\hline Follower sexual orientation & 1 & .134 & .158 & & 691 & & .000 & \\
\hline Follower biological gender & 1 & 19.410 & 22.932 & & .000 & & .026 & \\
\hline \multicolumn{9}{|l|}{ Focal variables } \\
\hline Same-sex leader's gender presentation (SSLGP) & 1 & .010 & .012 & & .912 & & .000 & \\
\hline Same-sex 1eaders' biological gender (SSLBG) & 1 & .127 & .150 & & 699 & & .000 & \\
\hline SSLGP $*$ SSLBG & 1 & .006 & .008 & & .931 & & .000 & \\
\hline Error & 862 & .846 & & & & & & \\
\hline \multicolumn{9}{|c|}{ Two-way ANCOVA analysis on follower conformity to leader influence attempts ${ }^{b}$} \\
\hline \multicolumn{9}{|l|}{ Covariates } \\
\hline Follower sexual orientation & 1 & 18.389 & & .285 & & .593 & & .000 \\
\hline Follower biological gender & 1 & 1039.639 & & 16.134 & & .000 & & .019 \\
\hline \multicolumn{9}{|l|}{ Focal variables } \\
\hline Same-sex leader's gender presentation (SSLGP) & 1 & 64.914 & & 1.007 & & .316 & & .001 \\
\hline Same-sex 1eaders' biological gender (SSLBG) & 1 & 182.247 & & 2.828 & & .093 & & .003 \\
\hline SSLGP $*$ SSLBG & 1 & 11.528 & & .179 & & .672 & & .000 \\
\hline Error & 851 & 64.437 & & & & & & \\
\hline
\end{tabular}

Follower sexual orientation $(0=$ heterosexual; $1=$ non-heterosexual $)$ and biological gender $(0=$ male; $1=$ female $)$ were dummy coded

$d f$, degree of freedom

${ }^{\mathrm{a}} R^{2}=.027$

${ }^{\mathrm{b}} R^{2}=.023$

two-tailed; $M_{\text {non-heterosexual }}=6.14 ; S D_{\text {non-heterosexual }}=0.92$; $\left.M_{\text {heterosexual }}=6.08 ; S D_{\text {heterosexual }}=0.93\right)$ or conformity to leader influence attempts $(t(860)=0.03, p=0.974$, twotailed; $M_{\text {non-heterosexual }}=13.95 ; S D_{\text {non-heterosexual }}=6.70$; $\left.M_{\text {heterosexual }}=13.98 ; S D_{\text {heterosexual }}=8.25\right)$. Thus, Hypothesis 4 was not supported.

Hypothesis 5 predicted that same-sex leaders' female followers would perceive them to be more effective (Hypothesis $5 a$ ) and exhibit more conformity (Hypothesis $5 b$ ) than their male followers. Supporting Hypothesis 5, independent $t$-test results, based on the four conditions in Study 2, indicate that female followers perceived same-sex leaders as more effective $\left(t(866)=4.85, p<0.01\right.$, two-tailed; $M_{\text {female }}=6.22$; $\left.S D_{\text {female }}=0.85 ; M_{\text {male }}=5.92 ; S D_{\text {male }}=0.99\right)$ and demonstrated more conformity to their leaders' influence attempts $\left(t(855)=3.96, p<0.01\right.$, two-tailed; $M_{\text {female }}=14.97$; $S D_{\text {female }}=8.91 ; M_{\text {male }}=12.79 ; S D_{\text {male }}=6.81$ ) than male followers.

Additionally, drawing from research on gender inversion (e.g., Herek, 2000; Kite \& Deaux, 1987; Madon, 1997; Taylor, 1983), we reasoned that one potential explanation for the unexpected finding that lesbian leaders received more follower (i.e., participant) conformity than gay leaders in Study 1 might be that participants in Study 1 assumed that the lesbian leader was more masculine and that the gay leader was more feminine. To the extent that masculinity is a stereotypically necessary leader quality, participants in Study 1 might have reacted more favorably to the lesbian leader. Followers' (i.e., participants') levels of conformity to the masculine lesbian leader and the feminine gay leader in the current study allow us to put this potential explanation to the test. Post hoc analysis results show that the masculine lesbian leader $(M=14.21$; $S D=6.69)$ received slightly more, but statistically insignificant $(F(1,421)=0.074, p=0.786)$, follower conformity than the feminine gay leader $(M=14.03 ; S D=7.51)$. Thus, the post hoc analysis results in Study 2 appear not to provide support for the potential explanation we gave in Study 1.

\section{Study 2: Discussion}

The main purpose of Study 2 was to examine whether leader gender presentation affected the intersection between leader same-sex sexual orientation and leader biological gender in influencing follower perceived leadership effectiveness and conformity to leader influence attempts, as well as whether follower characteristics intersected with leader same-sex sexual orientation. The findings of this study suggest that leader gender presentation plays no role in the intersection between leader same-sex sexual orientation and biological gender as far as follower leadership effectiveness perceptions and conformity to leader influence attempts are concerned. 
One possible explanation may be that followers categorized same-sex leaders as ineffective leaders and reacted accordingly regardless of their gender presentation and biological gender.

These findings suggest that the intersections of leaders' same-sex sexual orientation with their biological gender and gender presentation do not necessarily bring doubly worse outcomes. In other words, being gay and behaving femininely was not worse than being gay and behaving masculinely, and being lesbian and behaving masculinely was not worse than being lesbian and behaving femininely. In fact, additional analyses revealed that being gay and behaving masculinely, which has the closest resemblance with prototypical leaders, did not have better follower outcomes than any of the other three conditions (i.e., being lesbian and behaving masculinely, being lesbian and behaving femininely, and being gay and behaving femininely). These findings challenge widely held beliefs that marginalized identities (e.g., being women and being black) tend to interconnect in additive ways such that the addition of marginalized identities (e.g., black women) would produce even worse outcomes (Crenshaw, 1989, 1991; Rosette \& Livingston, 2012).

The results regarding the intersection between leader same-sex sexual orientation and follower sexual orientation suggest follower sexual orientation has no bearing on the influences of leader same-sex sexual orientation on followers. This may be because sexual minority followers did not regard sexual minority leaders as in-group members due to their status difference (Derks et al., 2016). This finding also is consistent with past research suggesting that similar to majority group members, minority group members also can hold biases toward other minority group members (e.g., Derks et al., 2015; Hekman et al., 2010).

In addition, consistent with our expectations, female followers appeared to be more tolerant and supportive of gay and lesbian leaders than their male counterparts. This finding stresses the importance of follower biological gender in comprehensively understanding the effects of leader samesex sexual orientation in the leadership process.

Finally, although not designed to test our explanation for the unexpected finding in Study 1 that lesbian leaders received more follower conformity than gay leaders, followers' levels of conformity to the masculine lesbian leader and the feminine gay leader in the current study help shed light on the validity of this explanation. The post hoc analysis indicates that the masculine lesbian leader and the feminine gay leader received similar levels of follower conformity, raising questions about the validity of our speculation for the unexpected finding in Study 1 and suggesting the likelihood of other plausible explanations for the unexpected finding.

Nevertheless, prior research suggests whereas masculinity is the appropriate gender role standard for males, "females who engage in both female and male gender behaviors are often seen in a positive light" (Schope \& Eliason, 2004, p. 77). Thus, gender inversion stereotypes-such as gays and lesbians exhibit prototypical mannerism of the opposite sex (e.g., Herek, 2000; Kite \& Deaux, 1987)—might have implicitly influenced Study 1 participants to react to the gay leader and the lesbian leader in such a way that they might have harshly punished the gay leader for not adhering to sex-role norms for men, but given little punishment to the lesbian leader or even rewarded the lesbian leader for being presumably masculine, a stereotypically necessary leader quality (e.g.,.g., Blashill \& Powlishta, 2009; Eagly \& Karau, 2002; Schope \& Eliason, 2004; Wong et al., 1999).

However, in Study 2, explicit information on the lesbian leader's masculinity ("rock-climbing, camping, and brewing craft beer") and the gay leader's femininity ("baking, reality TV, and repurposing vintage clothes and knick-knacks to sell on his (her) online store) might have drawn Study 2 participants' attention to the two leaders' same-sex sexual orientation, which violates the heteronormative standards for leaders (e.g., Fassinger et al., 2010; Pichler \& Holmes, 2017). As such, it is possible that both leaders had received harsh punishments from Study 2 participants and had been categorized as equally unqualified leaders (Lord et al., 1984). To the extent the foregoing reasoning is not far from the truth, Study 2 participants might have reacted similarly to the masculine lesbian leader and the feminine gay leader.

\section{Retests of Study 1 and Study 2}

The hypotheses in both Study 1 and Study 2 were tested using eLancers, specifically, Amazon's M-Turkers. Although data from eLancing platforms have been frequently used in organizational research (e.g., Caleo, 2016; Lanaj et al., 2014; Piccolo \& Colquitt, 2006), some argue that the use of eLancing samples, such as M-Turk samples, may limit the degree to which research findings will hold with target populations and suffer from range restriction, as M-Turkers were reported to be younger and driven by financial motivation, and self-select into studies (Cheung et al., 2017; Landers \& Behrend, 2015).

In addition, it is probable that asking study participants also to respond to our manipulation checks might have amplified our studies' demand characteristics making study participants aware of the focus of our research. Thus, as an attempt to address these concerns, we decided to redo Studies 1 and 2 with conventional samples and omit manipulation checks. In the following sections, we report Study 3 and Study 4, which repeat Study 1 and Study 2, respectively. 


\section{Study 3: Method}

\section{Participants}

We invited undergraduate students to recruit working adults who have full-time employment in U.S. organizations and report to a direct supervisor. Specifically, undergraduate students enrolled in two business courses at two large southeastern universities in the Spring semester of 2020 were asked to recruit study participants who met our inclusion criteria. In addition, half of the undergraduates who enrolled in a large business course at one of the two large southeastern universities in the Summer of 2020 were also invited to recruit study participants who met our inclusion criteria. In exchange, undergraduates in all of the three courses who recruited study participants received course credit, and those who could not or chose not to recruit study participants were given alternative assignments worth the same course credit.

In total, undergraduate students recruited 662 working adults and provided their contact information. We emailed all the recruits to invite them to take part in our research by clicking the link to our vignettes. The recruits were informed that their participation was voluntary, that their responses would be confidential, and that they were free to leave the research at any time. Four hundred and nine recruits participated in our research. Among those participants, 186 failed an attention check question and were excluded from the data collection process. The remaining 223 participants passed the attention check question and completed the survey. Of the 223 participants, 53\% were female, and $47 \%$ were male, and three individuals did not report their gender. The average age of the participants was 44 years old $(S D=12.17)$. Of the 223 participants, $34 \%$ reported working with gay or lesbian leaders, whereas $66 \%$ did not have such experience; $92 \%$ identified as heterosexual, and the remaining eight percent selected "other" as their sexual orientation.

As in Study 1, we used a $2 \times 2$ factorial between-subject experimental design with leader biological gender (i.e., male or female) and leader sexual orientation (i.e., samesex or heterosexual) as independent variables, and follower perceptions of leadership effectiveness and conformity to leader influence attempts as dependent variables, respectively. Participants were randomly selected into each of the four vignettes.

\section{Procedures and Measures}

Because the purpose of this portion of the current study is to re-examine Study 1 without manipulation checks, the exact same vignettes and procedures in Study 1 were used in the current study, Study 3, with the only exception that the manipulations of leaders' same-sex sexual orientation were not measured. In brief, participants were randomly assigned to read four vignettes in which leaders' same-sex sexual orientation and biological gender were manipulated using their first names (i.e., Robert and Mary) and their spouses' first names (i.e., Greg and Linda). After that, participants were asked to evaluate vignette leaders' effectiveness, complete a conformity task, and report their demographic information. Follower perceptions of leadership effectiveness $(\alpha=0.93)$ and conformity to leader influence attempts (the codes from two coders correlated at 0.95 ) were measured the same way as in Study 1.

\begin{tabular}{|c|c|c|c|c|c|}
\hline Variables & $d f$ & Mean square & $F$ & Significance & $\eta_{p}^{2}$ \\
\hline \multicolumn{6}{|c|}{ Two-way ANOVA analysis on follower perceptions of leadership effectiveness ${ }^{a}$} \\
\hline Leader sexual orientation (LSO) & 1 & 1.154 & 1.912 & .168 & .009 \\
\hline Leader biological gender (LBG) & 1 & 628 & 1.040 & .309 & .005 \\
\hline LSO * LBG & 1 & 1.411 & 2.336 & .128 & .011 \\
\hline Error & 219 & 604 & & & \\
\hline \multicolumn{6}{|c|}{ Two-way ANOVA analysis on follower conformity to leader influence attempts ${ }^{b}$} \\
\hline Leader sexual orientation (LSO) & 1 & 9.205 & .598 & .440 & .003 \\
\hline Leader biological gender (LBG) & 1 & 79.766 & 5.184 & .024 & .023 \\
\hline $\mathrm{LSO} * \mathrm{LBG}$ & 1 & .850 & .055 & .814 & .000 \\
\hline Error & 219 & 15.386 & & & \\
\hline
\end{tabular}

$d f$, degree of freedom

${ }^{\mathrm{a}} R^{2}=.022$

${ }^{\mathrm{b}} R^{2}=.027$ 


\section{Study 3: Results}

As shown in Table 3 (Two-way ANOVA analysis on follower perceptions of leadership effectiveness), the results of a two-way ANOVA on follower perceptions of leadership effectiveness show that neither the main effect of leader sexual orientation nor the main effect of leader biological gender was significant. The interaction between leader sexual orientation and biological gender was not significant. We further conducted planned contrast analyses, which show that there was no significant difference in leadership effectiveness $(F(1,219)=1.91, p=0.168)$ between same-sex leaders $(M=5.70 ; S D=0.85)$ and heterosexual $(M=5.84 ; S D=0.70)$ leaders. Thus, Hypothesis $l a$, which posited that leaders with same-sex sexual orientation would be perceived by followers as less effective than heterosexual leaders, was not supported.

Additionally, as summarized in Table 3 (Two-way ANOVA analysis on follower conformity to leader influence attempts), the results of a two-way ANOVA on follower conformity show that the main effect of leader biological gender was significant $(F(1,219)=5.18$, $p=0.024)$, whereas the main effect of leader sexual orientation and the interaction between leader sexual orientation and biological gender were not significant. Planned contrast analysis results indicate that there was no significant difference in follower conformity $(F(1,219)=0.60$, $p=0.440)$ between leaders with same-sex sexual orientation $(M=9.15 ; S D=3.69)$ and heterosexual leaders $(M=8.69 ; S D=4.00)$. Thus, Hypothesis $1 b$, which predicted that leaders with same-sex sexual orientation would receive less follower conformity to their influence attempts than heterosexual leaders, was not supported.

Hypothesis $2 a$ predicted that lesbian leaders would be perceived as less effective than gay leaders. The results of planned contrasts reveal that the difference in perceived leadership effectiveness between lesbian $(M=5.83$; $S D=0.79)$ and gay $(M=5.56 ; S D=0.91)$ leaders was not statistically significant at conventional levels $(F(1$, $219)=3.20, p=0.075)$. Thus, Hypothesis $2 a$ was not supported. Hypothesis $2 b$ predicted that lesbian leaders would receive less conformity to their influence attempts than gay leaders. The results of planned contrasts show that the difference in follower conformity between lesbian $(M=9.76 ; S D=3.28)$ and gay $(M=8.44 ; S D=3.91)$ leaders was not statistically significant at conventional levels $(F(1,219)=3.11, p=0.079)$. Thus, Hypothesis $2 b$ was not supported.

\section{Study 3: Discussion}

Study 3 was conducted to re-examine Study 1 with conventional samples and with the omission of manipulation checks. As summarized in Table 5, the significant findings in Study 1 that same-sex leaders were perceived as significantly less effective by followers and received significantly less follower conformity than heterosexual leaders were not reproduced in Study 3. The findings in Study 3 show that there were no significant differences in follower perceptions of leadership effectiveness and conformity to leader influence attempts between same-sex leaders and heterosexual leaders.

Among others, one possible explanation for the different findings between Study 1 and Study 3 could be that the manipulation check question in Study 1 might have drawn participants' attention to the vignette leaders' sexual orientation and then trigged their prejudice and discrimination against the samesex vignette leaders (Goodman et al., 2008). Prior research on derogatory remarks toward marginalized individuals provides some support for this explanation. Specifically, Goodman et al. (2008) reported that a male confederate gay undergraduate student received more negative evaluations when he was derogated by an experimenter as "being so gay" than when he appeared to be gay but didn't receive such a derogatory remark from the experimenter or when he appeared to be straight and didn't receive any derogatory remarks.

Thus, it was likely that our manipulation check question served as a derogatory remark that cued Study 1 M-Turkers to express their prejudice against same-sex individuals. Alternatively, it might be that participants in Study 3 were more mellow, rounded, and tolerant of differences as they were older than participants in Study 1 (Carstensen, 1991, 1992). If so, same-sex vignette leaders in Study 3 might have received less discrimination from participants in the forms of perceived leadership effectiveness and conformity than same-sex leaders in Study 1.

As in Study 1, being female did not make same-sex leaders (i.e., lesbian leaders) less effective or receive less conformity from followers. Different from the unexpected finding in Study 1, lesbian leaders did not receive significantly more conformity than gay leaders in Study 3. Taken together, the findings in Studies 1 and 3 raise questions on the additive perspective that is commonly used to understand the intersection of biological gender with other marginalized characteristics (e.g., Fassinger et al., 2010; Rosette \& Livingston, 2012). It appears that women who also possess other marginalized identities (e.g., having same-sex sexual orientation) have 
unique identities, which may not be the simple addition of two marginalized identities that produce doubly bad outcomes.

In summary, the significant findings in Study 1 were not reproduced in Study 3. Nevertheless, the effect sizes across Studies 1 and 3 are similar and small. For instance, as reported in Table 1 , the $\eta^{2}$ of leader same-sex sexual orientation was 0.009 and 0.003 respectively in Studies 1 and 3, suggesting that only $0.9 \%$ and $0.3 \%$ variance in follower conformity to leader influence attempt could be explained by leader same-sex sexual orientation respectively. Admittedly, the relatively small sample size in Study 3 reduced its power to detect statistically significant small effect sizes, which offers another potential explanation as to why the significant findings in Study 1 were not duplicated in Study 3.

\section{Study 4: Method}

\section{Participants}

Like in Study 3, we invited undergraduate students to recruit working adults who have full-time employment in U.S. organizations and report to a direct supervisor. In fact, the other half of the undergraduates who enrolled in the large business course at one of the two large southeastern universities in the Summer of 2020 were invited to recruit study participants who met our inclusion criteria for the current study. Likewise, those students who recruited study participants received course credit, and those who could not or chose not to recruit study participants were given alternative assignments worth the same amount of course credit.

In total, the undergraduate students recruited 350 working adults and provided their contact information. We emailed all the recruits to invite them to take part in our research by clicking on the link to our vignettes. The recruits were informed that their participation was voluntary, that their responses would be confidential, and that they were free to leave the research at any time. Two hundred ninety-five recruits participated in our research. Among those participants, 145 failed an attention check question and were excluded from the data collection process. The remaining 150 participants passed the attention check question and completed the survey. Of the 150 participants, $52 \%$ of the respondents were female, and $47 \%$ were male, and two individuals did not report their gender. The average age of the participants was 44 years old $(S D=11.03)$. Of the 150 participants, 35\% reported working with gay or lesbian leaders, whereas $65 \%$ did not have such experience; $92 \%$ reported to be heterosexual, and the remaining $8 \%$ selected "other" as their sexual orientation.
As in Study 2, we used a $2 \times 2$ factorial between-subject experimental design with same-sex leaders' gender expression (i.e., behaving masculinely or behaving femininely) and leader biological gender (i.e., male or female) as independent variables, and follower perceptions of leadership effectiveness and conformity to leader influence attempts as dependent variables, respectively. Participants were randomly selected into one of the four vignettes.

\section{Procedures and Measures}

The purpose of the current study is to reexamine Study 2 and omit manipulation checks. As such, the exact same vignettes and procedures in Study 2 were used in the current study, Study 4, with the only exception that the manipulations of same-sex leaders' masculinity and femininity were not measured. In short, participants were randomly assigned to read four vignettes in which same-sex leaders' gender presentation and biological gender were manipulated using their after-work hobbies (e.g., "rock climbing" vs. "repurposing vintage clothes and knick-knacks") and their first names (i.e., Robert vs. Mary). After that, participants were asked to evaluate vignette leaders' effectiveness, complete a conformity task, and report their demographic information. Follower perceptions of leadership effectiveness $(\alpha=0.92)$ and conformity to leader influence attempts (the codes from two coders correlated at 0.99) were measured the same way as in Study 2. As in Study 2, Follower sexual orientation was measured with a dummy variable (i.e., $0=$ heterosexual; $1=$ non-heterosexual), and follower biological gender was coded with a dummy variable with $0=$ male and $1=$ female.

\section{Study 4: Results}

Like in Study 2, two-way ANCOVA analyses with follower sexual orientation and biological gender as covariates were conducted. As shown in Table 4 (Two-way ANCOVA analysis on follower perceptions of leadership effectiveness), the main effects of same-sex leaders' biological gender and gender presentation were not significant, and the interaction between the two variables was not significant either. The results of planned contrasts show that there was not a significant difference between feminine $(M=5.67 ; S D=0.93)$ and masculine $(M=5.81 ; S D=0.68)$ gay leaders with respect to their leadership effectiveness $(F(1,141)=0.30, p=0.583)$. Thus, Hypothesis $3 a$, which predicted that feminine gay leaders would be perceived as less effective than masculine gay leaders, was not supported.

Additionally, the results of planned contrasts show that there was not a significant difference between masculine $(M=5.92 ; S D=0.79)$ and feminine $(M=5.74 ; S D=0.78)$ 
Table 4 Study 4 results

\begin{tabular}{|c|c|c|c|c|c|}
\hline Variables & $d f$ & Mean square & $F$ & Significance & $\eta_{p}^{2}$ \\
\hline \multicolumn{6}{|c|}{ Two-way ANCOVA analysis on follower perceptions of leadership effectiveness ${ }^{a}$} \\
\hline \multicolumn{6}{|l|}{ Covariates } \\
\hline Follower sexual orientation & 1 & .008 & .013 & .910 & .000 \\
\hline Follower biological gender & 1 & 1.372 & 2.235 & .137 & .016 \\
\hline \multicolumn{6}{|l|}{ Focal variables } \\
\hline Same-sex leader's gender presentation (SSLGP) & 1 & .815 & 1.328 & .251 & .009 \\
\hline Same-sex 1eaders' biological gender (SSLBG) & 1 & .235 & .382 & .537 & .003 \\
\hline SSLPG * SSLBG & 1 & .079 & .129 & .720 & .001 \\
\hline Error & 141 & 614 & & & \\
\hline \multicolumn{6}{|c|}{ Two-way ANCOVA analysis on follower conformity to leader influence attempts ${ }^{b}$} \\
\hline \multicolumn{6}{|l|}{ Covariates } \\
\hline Follower sexual orientation & 1 & 81.597 & 2.385 & .125 & .017 \\
\hline Follower biological gender & 1 & .929 & .027 & .869 & .000 \\
\hline \multicolumn{6}{|l|}{ Focal variables } \\
\hline Same-sex leader's gender presentation (SSLGP) & 1 & 117.945 & 3.447 & .065 & .024 \\
\hline Same-sex 1eaders' biological gender (SSLBG) & 1 & 45.045 & 1.317 & .253 & .009 \\
\hline SSLPG * SSLBG & 1 & 8.166 & .239 & .626 & .002 \\
\hline Error & 141 & 34.214 & & & \\
\hline
\end{tabular}

Follower sexual orientation $(0=$ heterosexual; $1=$ non-heterosexual $)$ and biological gender $(0=$ male; $1=$ female) were dummy coded

$d f$, degree of freedom

${ }^{\mathrm{a}} R^{2}=.025$

${ }^{\mathrm{b}} R^{2}=.051$

lesbian leaders with respect to their leadership effectiveness $(F(1,141)=1.19, p=0.277)$. Thus, Hypothesis $3 c$, which predicted that masculine lesbian leaders would be perceived as less effective than feminine lesbian leaders, was not supported.

Moreover, as summarized in Table 4 (Two-way ANCOVA analysis on follower conformity to leader influence attempts), the results of a two-way ANCOVA on follower conformity to leader influence attempts indicate that the main effect of same-sex leaders' gender presentation was not statistically significant at conventional levels ( $F(1$, $141)=3.447, p=0.065)$, and the main effect of same-sex leaders' biological gender and the interaction between same-sex leaders' biological gender and gender presentation was not significant. Planned contrasts were conducted to test Hypothesis $3 b$, which posited that feminine gay leaders would receive less follower conformity than masculine gay leaders. The results of planned contrasts show that there was not a significant $(F(1,141)=0.90, p=0.344)$ difference in follower conformity between feminine $(M=12.35$; $S D=6.34)$ and masculine $(M=13.68 ; S D=5.43)$ gay leaders. Thus, Hypothesis $3 b$ was not supported. In addition, the results of planned contrasts illustrate that the difference in follower conformity between masculine $(M=15.42$; $S D=6.18)$ and feminine $(M=12.92 ; S D=5.65)$ lesbian leaders was not statistically significant at conventional levels $(F(1,141)=2.87, p=0.093)$. Thus, Hypothesis $3 d$ was not supported.

Hypothesis 4 posited that same-sex leaders' heterosexual followers would perceive them as less effective (Hypothesis $4 a$ ) and exhibit less conformity (Hypothesis $4 b$ ) than their non-heterosexual followers. Based on the four conditions in Study 4, independent t-test results reveal that the difference in perceived leadership effectiveness between heterosexual followers $(M=5.80 ; S D=0.77)$ and non-heterosexual followers $(M=5.60 ; S D=1.03)$ was not statistically significant at conventional levels $(t(147)=0.85, p=0.395$, twotailed). Thus, Hypothesis $4 a$ was not supported. Different from Hypothesis $4 b$, there was not a significant difference ( $t$ $(147)=1.60, p=0.113$, two-tailed) in follower conformity to leader influence attempts between heterosexual followers $(M=13.80 ; S D=5.91)$ and non-heterosexual followers $(M=10.92 ; S D=7.01)$. Taken together, Hypothesis 4 was not supported.

Hypothesis 5 predicted that same-sex leaders' female followers would perceive them to be more effective (Hypothesis 5a) and exhibit more conformity (Hypothesis 5b) than their male followers. Independent t-test results based on the four conditions in Study 4 indicate that different from Hypothesis $5 a$, female followers $(M=5.88$; $S D=0.76)$ 
did not perceive same-sex leaders to be significantly more effective $(t(146)=1.39, p=0.168$, two-tailed) than male followers $(M=5.71 ; S D=0.79)$. Additionally, there was no significant difference in follower conformity to their leaders' influence attempts $(t(146)=-53, p=0.600$, twotailed) between female $(M=13.34 ; S D=5.92)$ and male $(M=13.85 ; S D=5.87)$ followers. Thus, Hypothesis $5 b$ was not supported.

In addition, like in Study 2, followers' (i.e., participants') conformity to the masculine lesbian leader and the feminine gay leader allowed us to test our speculation for the unexpected finding in Study 1 that lesbian leaders received more follower conformity than gay leaders. Post hoc results showed that there was no statistically significant difference $(F(1,83)=0.156, p=0.694)$ in follower conformity to the masculine lesbian leader $(M=13.19 ; S D=5.86)$ and the feminine gay leader $(M=13.68 ; S D=5.43)$. Again, the post hoc analyses in the current study did not provide support for the potential explanation we provided in Study 1.

\section{Study 4: Discussion}

The objective of Study 4 was to reexamine Study 2 with conventional samples while omitting manipulation checks. As shown in Table 5, consistent with Study 2, Study 4 did not find same-sex leaders' gender presentations that were consistent with gender inversion expectations led to worse outcomes: being perceived as less effective leaders by followers or receiving less follower conformity.

Similar to what was reported in Study 2, results in Study 4 indicate that followers' sexual orientation made no difference in their leadership effectiveness perceptions or their conformity to same-sex leaders' influence attempts. Given that the number of non-heterosexual followers $(N=18)$ in Study 4 was limited, we remind readers to interpret these findings with caution. With respect to follower biological gender, different from what was reported in Study 2, there were no differences between female and male followers regarding their perceptions of leadership effectiveness or conformity to same-sex leaders' influence attempts. This might be because female participants in Study 4 were older,
Table 5 Summary of hypothesis testing results and unexpected significant findings

\begin{tabular}{lll}
\hline Hypotheses & Study 1 & Study 3 \\
H1a & Supported & Not supported \\
H1b & Supported & Not supported \\
H2a & Not supported & Not supported \\
H2b & Not supported & Not supported \\
Unexpected significant findings & Lesbian leaders received more conformity to & None \\
& their influence attempts than gay leaders & \\
Hypotheses & Study 2 & Study 4 \\
H3a & Not supported & Not supported \\
H3b & Not supported & Not supported \\
H3c & Not supported & Not supported \\
H3d & Not supported & Not supported \\
H4a & Not supported & Not supported \\
H4b & Not supported & Not supported \\
H5a & Supported & Not supported \\
H5b & Supported & Not supported \\
Unexpected significant findings & None & None \\
\hline
\end{tabular}

Hypothesis 1: Compared with heterosexual leaders, leaders with same-sex sexual orientation tend to be perceived as lower in leadership effectiveness (1a) by their followers and receive less follower conformity to their influence attempts (1b). Hypothesis 2: Compared with gay leaders, lesbian leaders will (2a) be perceived as lower in leadership effectiveness by their followers and (2b) receive less follower conformity to their influence attempts. Hypothesis 3: For leaders with same-sex sexual orientation, their biological gender and gender presentation interact, such that feminine gay leaders tend to be perceived as lower in leadership effectiveness (3a) by their followers and receive less follower conformity to their influence attempts (3b) than masculine gay leaders, and that masculine lesbian leaders tend to be perceived as lower in leadership effectiveness (3c) by their followers and receive less follower conformity to their influence attempts (3d) than feminine lesbian leaders. Hypothesis 4: For leaders with same-sex sexual orientation, their heterosexual followers tend to perceive them as lower in leadership effectiveness (4a) and are less likely to conform to their influence attempts (4b) than their non-heterosexual followers. Hypothesis 5: For leaders with same-sex sexual orientation, their female followers tend to perceive them as higher in leadership effectiveness (5a) and are more likely to conform to their influence attempts (5b) than male followers 
more experienced, and/or less submissive or obedient than female participants in Study 2.

Taken together, the results in Studies 2 and 4 were largely similar. However, the significant findings that female followers perceived same-sex leaders to be more effective and showed more conformity than male followers in Study 2 were not found in Study 4. Apart from what was discussed above, the relatively small sample size in Study 4 could have reduced our power to detect statistically significant differences. For instance, the mean level of perceived leadership effectiveness by female followers (i.e., participants) was slightly higher than that by male followers (i.e., participants), albeit statistically insignificant.

Additionally, like in Study 2, our post hoc analyses indicate that followers (i.e., participants) in the current study reacted similarly to the masculine lesbian leader and the feminine gay leader with respect to conformity to the leaders' influence attempts, rendering no support for our speculation that the lesbian leader received more followers' conformity than the gay leader in Study 1, because of followers' assumed masculinity for the lesbian leader. Again, as discussed in Study 2, we suspect that explicit information on the lesbian leader's masculinity and the gay leader's femininity in the current study might have trigged study participants to focus on the leaders' sexual orientation and resulted in harsh punishments from the study participants on both leaders for their violation of the heteronormative standards for leaders (e.g., Fassinger et al., 2010; Pichler \& Holmes, 2017). Moreover, the relatively small sample size in the current study could also have lowered its power to identify significant results.

\section{General Discussion}

The overall purpose of this four-study investigation, based on over 2100 working adults in the U.S., was to repeatedly examine whether leaders' same-sex sexual orientation might affect followers' leadership perceptions and conformity to their influence attempts, and how the intersectionality of leaders' same-sex sexual orientation with leaders' gender orientation and followers characteristics may modify the influences of leaders' same-sex sexual orientation on followers' leadership perceptions and conformity to their influence attempts. The results across the four studies suggest that leaders' sexual orientations can have implications for the follower outcomes, that same-sex leaders with other marginalized identities (e.g., being women) may not suffer a double stigma penalization, and that female followers tend to react more positively to same-sex leaders than male followers.

Specifically, Study 1 showed that same-sex leaders received lower levels of follower perceptions of leadership effectiveness and less follower conformity than heterosexual leaders. However, being women did not produce worse follower outcomes for leaders with same-sex sexual orientation. On the contrary, being leaders with same-sex sexual orientation and being women (i.e., being lesbian leaders) had some advantages (i.e., more follower conformity) than being leaders with same-sex sexual orientation and being men (i.e., being gay leaders). Study 2 illustrated that same-sex leaders' gender presentation (behaving masculinely or femininely) did not make any difference in the intersection between leader same-sex sexual orientation and biological gender. Aimed at redoing Study 1, Study 3 did not reproduce the differences in the follower outcomes between same-sex and heterosexual leaders. Study 4 largely reproduced Study 2's results.

In addition, results in Study 2 show that followers' sexual orientation made no difference in their responses to samesex leaders, whereas followers' biological gender made some differences with female followers responding more positively than male followers. Study 4 reproduced similar results regarding the effects of follower sexual orientation. The exceptions are that female followers were found to have perceived same-sex leaders to be more effective and shown more conformity to leader influence attempts in Study 2 but not in Study 4.

Taken together, our large-scale and rigorous investigation of leaders' same-sex sexual orientation offers important implications for research and practice and suggests ample future research directions.

\section{Research Implications}

Collectively, the results of our four studies provide multiple thought-provoking research implications. To begin, our research contributes to the literature on leaders with marginalized characteristics by focusing on a concealable stigmatized identity: same-sex sexual orientation. The contrast findings on differences between same-sex and heterosexual leaders in Study 1 and Study 3 suggest social cues and contexts matter for concealable stigmatized identities. As noted in Study 3's discussion section, asking participants to recall vignette leaders' sexual orientation might have cued them to pay attention to this concealable identity and trigger their prejudice against vignette leaders with same-sex sexual orientation (Goodman et al., 2008). Our findings suggest that differences between concealable and non-concealable characteristics deserve careful attention in future research on leaders with marginalized characteristics.

Perhaps the most noteworthy and robust findings across the four studies are the largely unsupported intersection results. Together, these results suggest that same-sex leaders' visible subordinate characteristics (e.g., being female and behaving femininely) may not produce a double stigma penalization for same-sex leaders. The differences are largely inconsequential. In fact, having another subordinate characteristic (e.g., being women) may occasionally do same-sex 
leaders more good than harm. The pattern of our results was in stark contrast with major findings of prior research on the intersectionality of leaders' visible subordinate characteristics (e.g., black women leaders, Rosette \& Livingston, 2012). For instance, several studies have shown that being female results in worse outcomes for racial minority leaders (e.g., Key et al., 2012; Littrell \& Nkomo, 2005; Lynch, 2019; Rosette \& Livingston, 2012; Rosette et al., 2016). We suspect that the different patterns of intersectionality might be due to the concealability of leaders' same-sex sexual orientation. Clearly, more research is needed to better understand the different patterns.

Drawing from gender inversion research, we argued that the unexpected finding in Study 1, that the lesbian leader received more conformity than the gay leader, might have been due to higher levels of masculinity implicitly ascribed to the lesbian leader (Kite \& Deaux, 1987). However, post hoc analyses based on the masculine lesbian leader condition and the feminine gay leader condition in Study 2 and Study 4 did not provide support for our speculation in that both leaders received similar conformity across the two studies.

Alternatively, the intersectional invisibility perspective (Purdie-Vaughns \& Eibach, 2008; Smith et al., 2019) may help us understand the unexpected finding that lesbian leaders had better follower outcomes than gay leaders in Study 1. This perspective posits that individuals having multiple subordinate identities tend to be perceived as non-prototypical members of each of the constituent subordinate groups and thus become socially invisible. As such, these individuals may suffer less from stereotypes and prejudice toward prototypical members in each of the constituent subordinate groups and fair better than individuals having one constituent subordinate identity (Rosette \& Livingston, 2012). It follows that lesbian leaders are likely to have better outcomes than gay leaders because the former has two subordinate identities (i.e., being women and having same-sex sexual orientation), whereas the latter have one subordinate identity (i.e., having same-sex sexual orientation).

In addition, our findings offer important implications for Fassinger et al.'s (2010) theoretical model. To our knowledge, the present research represents one of the first attempts to validate Fassinger et al.'s multidimensional model of LGBT leadership enactment. To be clear, our research was only focused on "L" (lesbian) and "G" (gay) leaders and may not speak to "B" (bisexual) or " $T$ " (transgender) leaders. Nonetheless, we believe our findings still provide valuable knowledge on the validity of this model and suggestions for refinement. In general, our results indicate that leaders' same-sex sexual orientation can have significant influences on important follower outcomes and that leaders' gender orientation and follower worldviews measured with follower sexual orientation and biological gender also may intersect with leaders' same-sex sexual orientation. Our findings largely support the importance of the tenet of Fassinger et al.'s model but suggest some refinements to their model.

For instance, the inconsistent findings on the main effects of leaders' same-sex sexual orientation across Study 1 and Study 3 suggest the influences of leaders' same-sex orientation in the leadership process appear to be less blunt and direct than Fassinger et al. (2010) predicted. It might be because same-sex sexual orientation is not as visible as other stigmatized characteristics, such as being non-white or overweight, and that social cues might be needed to enact stigma toward same-sex leaders. Additionally, when discussing intersections of leaders' sexual orientation with leaders' gender orientation, Fassinger et al. (2010) appear to have relied on additive perspectives of intersectionality. Our findings render no support for the additive perspectives. Therefore, other perspectives such as interactive models and intersectional invisibility might be considered to refine intersections of leaders' same-sex sexual orientation with the other two dimensions in Fassinger et al.'s (2010) model. Last, given that the non-heterosexual orientations have different features (e.g., degree of concealability), it might be worthwhile to examine their roles in the leadership process individually.

To be noted, consistent with Fassinger et al.'s (2010) arguments, situations, such as followers' worldview measured with followers' biological gender, made differences in same-sex leaders' influences in the leadership process. Our results show that female followers could react more favorably to same-sex leaders than male followers, and that female followers could show more conformity to same-sex leaders' influence attempts than male followers. These significant findings provide evidence and support for calls to pay more research attention to followers in the leadership process (Shamir, 2007). Adding to prior research (e.g., Li et al., 2013), our investigation indicates followers are not interchangeable recipients of leader influence attempts and deserve more research attention (Wang et al., 2019).

Lastly, our research also sheds light on some similarities and differences, and pros and cons, between e-Lancing samples and conventional samples. Consistent with prior research on this topic (e.g., Cheung et al., 2017; Landers $\&$ Behrend, 2015), M-Turkers appear to be younger than conventionally recruited participants. It was convenient to recruit M-Turkers and faster to collect data. However, different from prior research's finding that e-Lancers were inattentive, our experience suggests that M-Turkers were more attentive than conventionally recruited participants in that a higher percentage of the latter failed the attention check question.

We suspect that the context of our data collection using the conventionally recruited participants might have contributed to their inattentiveness. They were invited to take part in our research at the early stage of the COVID-19 
pandemic, which disrupted their work and life and might have reduced their attention to a voluntary survey. In any event, we believe both sampling strategies have pros and cons, and using both sampling strategies to replicate findings is a strength of our and future research.

\section{Limitations and Future Research Directions}

Admittedly, this research has limitations that provide future research opportunities. Although the experimental methodology is advantageous to establishing causality, the generalizability of experimental findings needs further investigation. Given the nascence of this leadership topic (Fassinger et al., 2010), there are many opportunities for future research to cross-examine the generalizability of our findings. For instance, a non-experimental, or an alternate experimental approach, would be an important step to validate the generalizability of our findings. However, given the relatively small proportions of gay and lesbian leaders, as well as the potentially sensitive nature of the topic, a non-experimental investigation of leader sexual orientation undoubtedly would prove difficult.

For example, researchers would need to consider the ethical implications of gathering information from followers who perceive their leaders to be gay or lesbian. Further, gathering an adequate sample of out gay and lesbian leaders who would be willing to participate in this type of research might be a challenge. Because of challenges such as this, we felt justified in using a "paper leader" methodology (Aguinis \& Bradley, 2014). However, if future researchers cannot gather organizational data, they potentially could consider an alternative (e.g., video recording) to a paper leader experimental design. To be noted, since we just gave participants three minutes to write down uses of brick or wood, our conformity measure was susceptible to a ceiling effect. We recommend future research gives participants longer time to engage in experimental activities.

The vignettes we used in our studies placed our participants in a work setting that may have been conducive to some of the factors that led to the results we found. For example, lesbian leaders were found to have received more conformity to their influence attempts than gay leaders. The style, behavior, and perceived skills of the female leaders, lesbian or not, may have been more congruent with the nature of our hypothetical workplace. Researchers should consider manipulating the situation to explain "the conditions that support or penalize leaders who self-identify as sexual minorities" (Fassinger et al., 2010, p. 213). One relevant situational factor is organizational culture, especially organizational inclusive culture.
As one of the initial attempts in this area, we only focused on leaders' same-sex sexual orientation in the current research. Researchers are encouraged to examine the role of other sexual minority leaders such as bisexual and transgender leaders in shaping follower outcomes. Additionally, it is perplexing that more than $30 \%$ of participants reported having experience working with gay or lesbian leaders across the four studies. Some research suggests that due to the concealable nature of sexual orientation, people tend to deduce others' sexual orientation to be homosexual when information about others' sexual orientation is unavailable (Blashill \& Powlishta, 2009).

Nevertheless, we encourage future research to investigate why a relatively large proportion of workers have worked with gay or lesbian leaders. In addition, we do not know the implications of working with same-sex leaders over time. Future research is needed to examine whether negative perceptions of same-sex leaders are salient in the short term or if these perceptions dissipate as followers have extended interactions with their leader. Finally, given that the sample sizes in Studies 3 and 4 are much smaller than those in Studies 1 and 2, we remind readers not to take the former as rigorous replications of the latter. To remedy this limitation, we encourage future researchers to replicate Studies 1 and 2 with comparable conventional samples.

\section{Practical Implications}

Our findings across the four studies offer important managerial implications. To begin, the results in Study 1 suggest that it is likely that simply because of their non-prototypical sexual orientation, same-sex leaders are perceived to be less effective and receive less follower conformity than heterosexual leaders. Superiors of same-sex leaders need to be aware of this possibility, especially for same-sex leaders whose followers are relatively young. Extra care (e.g., giving less weight to follower ratings) needs to be taken to ensure same-sex leaders are fairly evaluated in performance reviews.

Moreover, the largely inconsequential effects of gay and lesbian leaders' gender presentation reported in Studies 2 and 4 suggest organizations may encourage gay and lesbian leaders to freely express their gender identity. This may reduce sexual minority leaders' stress of not being able to present their true gender identity at work and increase their self-confidence, which may, in turn, strengthen their leadership effectiveness (De Cremer \& van Knippenberg, 2004).

In addition, findings across the four studies suggest managers with same-sex sexual orientation need to be aware that different followers react to their leadership differently. Specifically, female followers tend to be more supportive of them than male followers. Sexual minority managers are 
advised to increase communications with followers, especially male followers to enhance understandings and support. Thus, there are ethical concerns surrounding discrimination in the hiring or promotion of same-sex leaders as well as the hiring of followers. Although the U.S. Supreme Court has legalized many LGBT rights, these rights continue to vary by state and jurisdiction. Recent research has suggested that laws prohibiting discrimination in the workplace based on sexual orientation and gender identity spurs innovation and leads to higher firm performance (Hossain et al., 2019). Thus, continued research on diversity such as LGBT issues in the workplace remains important for organizations.

\section{Conclusions}

This four-study investigation advances knowledge on the role of leaders' same-sex sexual orientation in the leadership process. We found leaders' same-sex sexual orientation could negatively impact their leadership effectiveness. However, same-sex leaders didn't appear to suffer a double stigma penalization by having additional subordinate identities (e.g., also being women). Female followers could be more supportive of same-sex leaders than male followers. Our findings offer meaningful implications for research and practice, and we hope this reserach stimulates further work in this important area in the future.

\section{Appendix 1. A Sample Vignette Used in Study 1}

You are a member of the marketing department of D\&S Marketing LLC, located in New York City. The department consists of 8 people in total: you, your team members, and the manager of the department, Robert Johnson. Robert has been the head of this unit for a few years now. He and his spouse, Greg, like to go to the movies and travel as often as their schedules allow.

Robert is an individual who opposes the "status quo" and seeks to do things in untraditional ways. Before taking over as manager, he either received or was nominated for multiple regional and national marketing awards for his creative campaigns. This unconventional mindset, fueled by a disregard for the "norm" has carried into Robert's management style. At a recent company event, your co-worker introduced Robert with a sentiment that is shared within your department: "He is always challenging us to think outside of the box, to view things from multiple angles, and to push the limits of our own creativity."

Though Robert is all about being unconventional, he does not alienate members of the department by having undefined directions for the future. In fact, Robert's vision for the future of the department is very clear. On top of that, he has the personality to not only articulate this vision, but also to inspire you to follow. Weekly meetings with Robert are not the dull, hour-wasters that are so typical elsewhere. Because of his clear plan for the team, as well as the conviction with which he relays this message, these meetings are typically very motivating. Robert is an easy leader to follow, and is the type of leader that many in the department would hope to become someday.

Acknowledgements We gratefully acknowledge the financial support for this research we received from the Marie Krafft fund, Florida State University Research Foundation.

\section{Declarations}

Ethics Approval Our research complies with ethical standards. Specifically, our use of human subjects was approved by the Florida State University Institutional Review Board (IRB number: IRB00000446; humansubjects@fsu.edu).

Conflict of Interest The authors declare no conflict of interest.

\section{References}

Aguinis, H., \& Bradley, K. J. (2014). Best practice recommendations for designing and implementing experimental vignette methodology studies. Organizational Research Methods, 17(4), 351-371.

Aguinis, H., \& Lawal, S. O. (2012). Conducting field experiments using eLancing's natural environment. Journal of Business Venturing, 27, 493-505.

Aguinis, H., \& Lawal, S. O. (2013). eLancing: A review and research agenda for bridging the science-practice gap. Human Resource Management Review, 23(1), 6-17.

Avery, D. R., McKay, P. F., Volpone, S. D., \& Malka, A. (2015). Are companies beholden to bias? The impact of leader race on consumer purchasing behavior. Organizational Behavior and Human Decision Processes, 127, 85-102.

Avolio, B. J. (2007). Promoting more integrative strategies for leadership theory-building. American Psychologist, 62, 25-33.

Bartol, K. M., Evans, C. J., \& Stith, M. T. (1978). Black versus white leaders: A comparative review of the literature. Academy of Management Review, 3(2), 293-304.

Bass, B. M. (1985). Leadership and performance beyond expectations. Free Press: Collier Macmillan.

Bialik, C. (April 15, 2011). Sexual stats in the post-Kinsey age. The Wall Street Journal.

Blashill, A. J., \& Powlishta, K. K. (2009). The impact of sexual orientation and gender role on evaluations of men. Psychology of Men \& Masculinity, 10, 160-173.

Breslin, R. A., Pandey, S., \& Riccucci, N. M. (2017). Intersectionality in public leadership research: A review and future research agenda. Review of Public Personnel Administration, 37, 160-182.

Burns, C., \& Krehely, J. (2011). Gay and transgender people face high rates of workplace discrimination and harassment. Working paper, Center for American Progress.

Caleo, S. (2016). Are organizational justice rules gendered? Reactions to men's and women's justice violations. Journal of Applied Psychology, 101, 1422-1435. 
Carstensen, L. L. (1991). Selectivity theory: Social activity in life-span context. Annual Review of Gerontology and Geriatrics, 11(1), 195-217.

Carstensen, L. L. (1992). Social and emotional patterns in adulthood: Support for socioemotional selectivity theory. Psychology and Aging, 7(3), 331-338.

Chatman, J. A. (1991). Matching people and organizations: Selection and socialization in public accounting firms. Administrative Science Quarterly, 36, 459-484.

Cheung, J. H., Burns, D. K., Sinclair, R. R., \& Sliter, M. (2017). Amazon Mechanical Turk in organizational psychology: An evaluation and practical recommendations. Journal of Business and Psychology, 32(4), 347-361.

Clausell, E., \& Fiske, S. T. (2005). When do subgroup parts add up to the stereotypic whole? Mixed stereotype content for gay male subgroups explains overall ratings. Social Cognition, 23, $161-181$.

Cole, E. R. (2009). Intersectionality and research in psychology. American Psychologist, 64(3), 170-180.

Colella, A., \& Stone, D. L. (2005). Workplace discrimination toward persons with disabilities: A call for some new research directions. In R. L. Dipboye \& A. Colella (Eds.), Discrimination at work: The psychological and organizational bases (pp. 227-253). Taylor \& Francis.

Conger, J. A., \& Kanungo, R. N. (1987). Toward a behavioral theory of charismatic leadership in organizational settings. Academy of Management Review, 12, 637-647.

Crenshaw, K. (1989). Demarginalizing the intersection of race and sex: A black feminist critique of antidiscrimination doctrine, feminist theory and antiracist politics (pp. 139-168). University of Chicago.

Crenshaw, K. (1991). Mapping the margins: Intersectionality, identity politics, and violence against women of color. Stanford Law Review, 43, 1241-1299.

De Cremer, D., \& Van Knippenberg, D. (2004). Leader self-sacrifice and leadership effectiveness: The moderating role of leader selfconfidence. Organizational Behavior and Human Decision Processes, 95(2), 140-155.

DeRue, D. S., Nahrgang, J. D., Wellman, N. E. D., \& Humphrey, S. E. (2011). Trait and behavioral theories of leadership: An integration and meta-analytic test of their relative validity. Personnel Psychology, 64(1), 7-52.

Derks, B., Van Laar, C., \& Ellemers, N. (2016). The queen bee phenomenon: Why women leaders distance themselves from junior women. The Leadership Quarterly, 27(3), 456-469.

Derks, B., Laar, C., Ellemers, N., \& Raghoe, G. (2015). Extending the queen bee effect: How Hindustani workers cope with disadvantage by distancing the self from the group. Journal of Social Issues, 71(3), 476-496.

Dodge, K. A., Gilroy, F. D., \& Fenzel, L. M. (1995). Requisite management characteristics revisited: Two decades later. Journal of Social Behavior and Personality, 10(4), 253-264.

Duehr, E. E., \& Bono, J. E. (2006). Men, women, and managers: Are stereotypes finally changing? Personnel Psychology, 59, 815-846.

Eagly, A. H. (1987). Reporting sex differences. American Psychologist, 42, 756-757.

Eagly, A. H., \& Chin, J. L. (2010). Diversity and leadership in a changing world. American Psychologist, 65(3), 216-224.

Eagly, A. H., \& Johannesen-Schmidt, M. C. (2001). The leadership styles of women and men. Journal of Social Issues, 57, 781-797.

Eagly, A. H., \& Johnson, B. T. (1990). Gender and leadership style: A meta-analysis. Psychological Bulletin, 108, 233-256.
Eagly, A. H., \& Karau, S. J. (1991). Gender and the emergence of leaders: A meta-analysis. Journal of Personality and Social Psychology, 60(5), 685-710.

Eagly, A. H., \& Karau, S. J. (2002). Role congruity theory of prejudice toward female leaders. Psychological Review, 109, 573-598.

Eagly, A. H., Karau, S. J., \& Makhijani, M. G. (1995). Gender and the effectiveness of leaders: A meta-analysis. Psychological Bulletin, $117(1), 125-145$.

Ellis, H. (1927). Studies in the psychology of sex volume II: Sexual inversion (3rd Ed.). Dortmund, Germany: Project Gutenberg.

Fassinger, R. E., Shullman, S. L., \& Stevenson, M. R. (2010). Toward an affirmative lesbian, gay, bisexual, and transgender leadership paradigm. American Psychologist, 65(3), 201-215.

French, J. R., Raven, B., \& Cartwright, D. (1959). The bases of social power. Classics of Organization Theory, 7, 311-320.

Frick, J. W., Guilford, J. P., Christensen, P. R., \& Merrifield, P. R. (1959). A factor-analytic study of flexibility in thinking. Educational and Psychological Measurement, 19, 469-495.

Giessner, S. R., \& van Knippenberg, D. (2008). "License to fail": Goal definition, leader group prototypicality, and perceptions of leadership effectiveness after leader failure. Organizational Behavior and Human Decision Processes, 105(1), 14-35.

Goodman, J. A., Schell, J., Alexander, M. G., \& Eidelman, S. (2008). The impact of a derogatory remark on prejudice toward a gay male leader. Journal of Applied Social Psychology, 38, 542-555.

Grinnell, J. P. (2002). Effects of leaders' and evaluators' sex on sexrole stereotyping of charismatic leaders. Psychological Reports, $91,1247-1252$.

Grzanka, P. R., \& Miles, J. R. (2016). The problem with the phrase "intersecting identities": LGBT affirmative therapy, intersectionality, and neoliberalism. Sexuality Research and Social Policy, $13,371-389$.

Guilford, J. P. (1975). Varieties of creative giftedness, their measurement and development. Gifted Child Quarterly, 19, 107-121.

Hekman, D. R., Aquino, K., Owens, B. P., Mitchell, T. R., Schilpzand, P., \& Leavitt, K. (2010). An examination of whether and how racial and gender biases influence customer satisfaction. Academy of Management Journal, 53(2), 238-264.

Herek, G. M. (2000). The psychology of sexual prejudice. Current Directions in Psychology Science, 9, 19-22.

Herek, G. M. (2002). Heterosexuals' attitudes toward bisexual men and women in the United States. Journal of Sex Research, 39(4), 264-274.

Herek, G. M. (2007). Confronting sexual stigma and prejudice: Theory and practice. Journal of Social Issues, 63, 905-925.

Herek, G. M. (2008). Sexual prejudice. In T. Nelson (Ed.), Handbook of prejudice (pp. 439-465). Lawrence Erlbaum.

Hill, A. D., Upadhyay, A. D., \& Beekun, R. I. (2015). Do female and ethnically diverse executives endure inequity in the CEO position or do they benefit from their minority status? An Empirical Examination. Strategic Management Journal, 36(8), 1115-1134.

Hochwarter, W. A., Ferris, G. R., \& Hanes, T. J. (2011). Multi-study packages in organizational science research. In D. J. Ketchen \& D. D. Bergh (Eds.), Building methodological bridges: Research methodology in strategy and management (Vol. 6, pp. 163-199). Emerald Group Publishing Limited.

Hossain, M., Atif, M., Ahmed, A., \& Mia, L. (2019). Do LGBT workplace diversity policies create value for firms? Journal of Business Ethics. https://doi.org/10.1007/s10551-019-04158-z

Hoye, G., \& Lievens, F. (2003). The effects of sexual orientation on hirability ratings: An experimental study. Journal of Business and Psychology, 18(1), 15-30.

Jeong, S. H., \& Harrison, D. A. (2017). Glass breaking, strategy making, and value creating: Meta-analytic outcomes of women as 
CEOs and TMT members. Academy of Management Journal, 60(4), 1219-1252.

Johnson, S. K., Murphy, S. E., Zewdie, S., \& Reichard, R. J. (2008). The strong, sensitive type: Effects of gender stereotypes and leadership prototypes on the evaluation of male and female leaders. Organizational Behavior and Human Decision Processes, 106(1), 39-60.

Keith, V. M., Nguyen, A. W., Taylor, R. J., Mouzon, D. M., \& Chatters, L. M. (2017). Microaggressions, discrimination, and phenotype among African Americans: A latent class analysis of the impact of skin tone and BMI. Sociological Inquiry, 87(2), 233-255.

Key, S., Popkin, S., Munchus, G., Wech, B., Hill, V., \& Tanner, J. (2012). An exploration of leadership experiences among white women and women of color. Journal of Organizational Change Management, 25(3), 392-404.

King, E. B., Mohr, J. J., Peddie, C. I., Jones, K. P., \& Kendra, M. (2017). Predictors of identity management: An exploratory experience-sampling study of lesbian, gay, and bisexual workers. Journal of Management, 43, 476-502.

Kite, M. E., \& Deaux, K. (1987). Gender belief systems: Homosexuality and the implicit inversion theory. Psychology of Women Quarterly, 11(1), 83-96.

Klein, F., Sepekoff, B., \& Wolf, T. J. (1985). Sexual orientation: A multi-variable dynamic process. Journal of Homosexuality, $11(1-2), 35-49$.

Koch, A., D'Mello, S., \& Sackett, R. (2015). A meta-analysis of gender stereotypes and bias in experimental simulations of employment decision making. Journal of Applied Psychology, 100(1), $128-161$.

Koenig, A. M., Eagly, A. H., Mitchell, A. A., \& Ristikari, T. (2011). Are leader stereotypes masculine? A meta-analysis of three research paradigms. Psychological Bulletin, 137, 616-642.

Krupat, K., \& McCreery, P. (2001). Out at work: Building a gay-labor alliance. In Cultural Politics (Vol. 17). University of Minnesota Press. Minneapolis, London.

Lanaj, K., Johnson, R. E., \& Barnes, C. M. (2014). Beginning the workday yet already depleted? Consequences of late-night smartphone use and sleep. Organizational Behavior and Human Decision Processes, 124(1), 11-23.

Landers, R. N., \& Behrend, T. S. (2015). An inconvenient truth: Arbitrary distinctions between organizational, Mechanical Turk, and other convenience samples. Industrial and Organizational Psychology, 8(2), 142-164.

Lehavot, K., \& Lambert, A. J. (2007). Toward a greater understanding of antigay prejudice: On the role of sexual orientation and gender role violation. Basic and Applied Social Psychology, 29(3), 279-292.

Lewis, K. M. (2000). When leaders display emotion: How followers respond to negative emotional expression of male and female leaders. Journal of Organizational Behavior, 21(2), 221-234.

Li, N., Chiaburu, D. S., Kirkman, B. L., \& Xie, Z. (2013). Spotlight on the followers: An examination of moderators of relationships between transformational leadership and subordinates' citizenship and taking charge. Personnel Psychology, 66(1), 225-260.

Littrell, R. F., \& Nkomo, S. M. (2005). Gender and race differences in leader behaviour preferences in South Africa. Women in Management Review, 20(8), 562-580.

Livingston, R. W., Rosette, A. S., \& Washington, E. F. (2012). Can an agentic Black woman get ahead? The impact of race and agentic emotional expression on female leader status. Psychological Science, 23(4), 354-358.

Lord, R. G., Foti, R. G., \& De Vader, C. L. (1984). A test of leadership categorization theory: Internal structure, information processing, and leadership perceptions. Organizational Behavior and Human Performance, 34, 343-378.
Lord, R. G., \& Maher, K. J. (1993). Leadership and information processing: Linking perceptions and performance. Routledge.

Lord, R. G., Phillips, J. S., \& Rush, M. C. (1980). Effects of sex and personality on perceptions of emergent leadership, influence, and social power. Journal of Applied Psychology, 65(2), 176-182.

Lynch, E. H. (2019). An exploration of contextual factors of weightbased discrimination against business leaders. Unpublished doctoral dissertation, University of Missouri-St. Louis.

Madon, S. (1997). What do people believe about gay males? A study of stereotype content and strength. Sex Roles, 37(9-10), 663-685.

Martinez, L. R., Ruggs, E. N., Sabat, I. E., Hebl, M. R., \& Binggeli, S. (2013). The role of organizational leaders in sexual orientation equality at organizational and federal levels. Journal of Business and Psychology, 28(4), 455-466.

McKay, P. F., Avery, D. R., \& Morris, M. A. (2009). A tale of two climates: Diversity climate from subordinates' and managers' perspectives and their role in store unit sales performance. Personnel Psychology, 62, 767-791.

Ospina, S., \& Foldy, E. (2009). A critical review of race and ethnicity in the leadership literature: Surfacing context, power and the collective dimensions of leadership. The leadership quarterly, 20(6), 876-896.

Pellegrini, V., De Cristofaro, V., Giacomantonio, M., \& Salvati, M. (2020). Why are gay leaders perceived as ineffective? The role of the type of organization, sexual prejudice and gender stereotypes. Personality and Individual Differences, 157(109817), 1-11.

Piccolo, R. F., \& Colquitt, J. A. (2006). Transformational leadership and job behaviors: The mediating role of core job characteristics. Academy of Management Journal, 49, 327-340.

Pichler, S., \& Holmes, O., IV. (2017). An investigation of fit perceptions and promotability in sexual minority candidates. Equality, Diversity and Inclusion, 36(7), 628-646.

Platt, L. F., \& Lenzen, A. L. (2013). Sexual orientation microaggressions and the experience of sexual minorities. Journal of Homosexuality, 60(7), 1011-1034.

Porath, C. L., \& Erez, A. (2007). Does rudeness really matter? The effects of rudeness on task performance and helpfulness. Academy of Management Journal, 50, 1181-1197.

Powell, G. N., Butterfield, D. A., \& Bartol, K. M. (2008). Leader evaluations: A new female advantage? Gender in Management: An International Journal, 23(3), 156-174.

Purdie-Vaughns, V., \& Eibach, R. P. (2008). Intersectional invisibility: The distinctive advantages and disadvantages of multiple subordinate-group identities. Sex Roles, 59(5-6), 377-391.

Ragins, B. R. (1989). Power and gender congruency effects in evaluations of male and female managers. Journal of Management, $15,65-76$.

Ragins, B. R., \& Cornwell, J. M. (2001). Pink triangles: Antecedents and consequences of perceived workplace discrimination against gay and lesbian employees. Journal of Applied Psychology, 86, $1244-1261$.

Rahim, M. A. (1989). Relationships of leader power to compliance and satisfaction with supervision: Evidence from a national sample of managers. Journal of Management, 15(4), 545-556.

Reece, R. L. (2019). Coloring weight stigma: On race, colorism, weight stigma, and the failure of additive Intersectionality. Sociology of Race and Ethnicity, 5(3), 388-400.

Rosette, A. S., Leonardelli, G. J., \& Phillips, K. W. (2008). The White standard: Racial bias in leader categorization. Journal of Applied Psychology, 93(4), 758-777.

Rosette, A. S., \& Livingston, R. W. (2012). Failure is not an option for Black women: Effects of organizational performance on leaders with single versus dual-subordinate identities. Journal of Experimental Social Psychology, 48(5), 1162-1167. 
Rosette, A. S., Koval, C. Z., Ma, A., \& Livingston, R. (2016). Race matters for women leaders: Intersectional effects on agentic deficiencies and penalties. The Leadership Quarterly, 27(3), 429-445.

Ryan, M. K., \& Haslam, S. A. (2007). The glass cliff: Exploring the dynamics surrounding the appointment of women to precarious leadership positions. Academy of Management Review, 32(2), 549-572.

Schope, R. D., \& Eliason, M. J. (2004). Sissies and tomboys: Gender role behaviors and homophobia. Journal of Gay \& Lesbian Social Services, 16(2), 73-97.

Schuh, S. C. (2014). Gender differences in leadership role occupancy: The mediating role of power motivation. Journal of Business Ethics, 120(3), 363-379.

Shamir, B. (2007). From passive recipients to active co-producers: Followers' roles in the leadership process. In B. Shamir, R. Pillai, M. Bligh, \& M. Uhl-Bien (Eds.), Follower-centered perspectives on leadership: A tribute to the memory of James R. Meindl (pp. 9-39). Information Age Publishers.

Shields, S. A. (2008). Gender: An intersectionality perspective. Sex Roles, 59, 301-311.

Shinar, E. H. (1975). Sexual stereotypes of occupations. Journal of Vocational Behavior, 7(1), 99-111.

Smith, A. N., Watkins, M. B., Ladge, J. J., \& Carlton, P. (2019). Making the invisible visible: Paradoxical effects of intersectional invisibility on the career experiences of executive Black women. Academy of Management Journal, 62(6), 1705-1734.

Snyder, K. (2006). The G quotient: Why gay executives are excelling as leaders... and what every manager needs to know. Jossey-Bass.

Sy, T., Shore, L. M., Strauss, J., Shore, T. H., Tram, S., Whiteley, P., \& Ikeda-Muromachi, K. (2010). Leadership perceptions as a function of race-occupation fit: The case of Asian Americans. Journal of Applied Psychology, 95(5), 902-919.

Tajfel, H., \& Turner, J. C. (1985). The social identity theory of intergroup behavior. In S. Worchel \& W. G. Austin (Eds.), Psychology of Intergroup Relations (pp. 7-24). Nelson-Hall.

Taylor, M. A. (1983). Conceptions of masculinity and femininity as a basis for stereotypes of male and female homosexuals. Journal of Homosexuality, 9, 37-53.
Taylor, M. A. (1998). The masculine soul heaving in the female bosom: Theories of inversion and the well of loneliness. Journal of Gender Studies, 7(3), 287-296.

Tepper, B. J. (2000). Consequences of abusive supervision. Academy of Management Journal, 43(2), 178-190.

Vlachos, P. A., Panagopoulos, N. G., \& Rapp, A. A. (2013). Feeling good by doing good: Employee CSR-induced attributions, job satisfaction, and the role of charismatic leadership. Journal of Business Ethics, 118(3), 577-588.

Wang, G., Holmes, M. R., Jr., Devine, R. A., \& Bishoff, J. (2018). CEO gender differences in careers and the moderating role of country culture: A meta-analytic investigation. Organizational Behavior and Human Decision Processes, 148, 30-53.

Wang, G., Van Iddekinge, C. H., Zhang, L., \& Bishoff, J. (2019). Metaanalytic and primary investigations of the role of followers in ratings of leadership behavior in organizations. Journal of Applied Psychology, 104(1), 70-106.

Warner, M. (1991). Introduction: Fear of a queer planet. Social Text, 29, 3-17.

Wong, F. Y., McCreary, D. R., Carpenter, K. M., Engle, A., \& Korchynsky, R. (1999). Gender-related factors influencing perceptions of homosexuality. Journal of Homosexuality, 37(3), 19-31.

Yoder, J. D. (2001). Making leadership work more effectively for women. Journal of Social Issues, 57, 815-828.

Yukl, G. (2010). Leadership in organizations (7th ed.). Prentice Hall.

Zapata, C. P., Carton, A. M., \& Liu, J. T. (2016). When justice promotes injustice: Why minority leaders experience bias when they adhere to interpersonal justice rules. Academy of Management Journal, 59(4), 1150-1173.

Publisher's Note Springer Nature remains neutral with regard to jurisdictional claims in published maps and institutional affiliations. 